\title{
A mobilização cívica e política na era das redes sociais: uma análise da ação de movimentos sociais no Facebook ${ }^{1}$
}

$\overline{\text { João Carlos Sousa }}{ }^{2}$ (iD)
Ricardo Morais ${ }^{3}$ (i)

\begin{abstract}
Neste artigo analisa-se o papel do Facebook como ferramenta articuladora de práticas cotidianas no seio dos movimentos sociais, quer na sua organização interna, quer na comunicação e interação com elementos externos. A metodologia mista implementada passa por: análise de conteúdo das páginas de Facebook dos oito movimentos estudados e realização de seis entrevistas presenciais com ativistas. Os resultados principais revelam que existe uma forte ancoragem dos movimentos ao quadro político mais amplo de crise social e política e de intervenção da Troika, assumindo como principal objetivo a sua contestação. Embora bem-sucedidos na mobilização da população portuguesa, a verdade é que o fulgor mobilizador se circunscreveu no tempo. O modelo construído revelou-se robusto e flexível, o que possibilita a sua replicação em pesquisas futuras no âmbito da sociologia política.
\end{abstract}

Palavras-chave: mobilização cívica; participação política; redes sociais; Facebook

\section{Introdução}

A 15 de setembro de 2012, em resultado de uma crescente agitação social de uma larga parte da população portuguesa, e na sequência do pedido de ajuda feito à Troika ${ }^{4}$, realizou-se aquela que ficou conhecida na história recente de Portugal como a maior manifestação após o Prec (Período Revolucionário em Curso) (Accornero e Pinto,

\footnotetext{
${ }^{1}$ Esta é uma publicação escrita em português europeu.

2 Instituto Universitário de Lisboa (ISCTE-IUL), Centro de Investigação e Estudos de Sociologia. Lisboa, Portugal. E-mail: <joao.carlos.sousa@iscte-iul.pt>.

3 Universidade da Beira Interior. Faculdade de Artes e Letras. Covilhã, Portugal.

E-mail: <rm.ricardomorais@gmail.com>.

${ }^{4} \mathrm{O}$ pedido de ajuda foi feito ainda na vigência do governo liderado por José Sócrates, do Partido Socialista (PS), e depois de o presidente do PSD (Partido Social-Democrata), Pedro Passos Coelho, ter chumbado o PEC 4 (Programa de Estabilidade e Crescimento), que tinha sido concebido pelo governo português com o beneplácito da União Europeia, enquanto conjunto de medidas de corte da despesa pública. O chumbo, com base na ideia de que as medidas não correspondiam às verdadeiras necessidades da sociedade portuguesa, levaria à demissão do então primeiro ministro José Sócrates, à marcação de eleições legislativas e ao início de um novo ciclo político com o XIX Governo Constitucional, formado por uma coligação entre PSD e CDS-PP (Centro Democrático Social-Partido Popular) e aplicação de medidas de austeridade igualmente penalizadoras para a população.
} 
2015a, 2015b), calculando-se que nela participaram cerca de meio milhão de pessoas ${ }^{5}$. A manifestação despertou impulsionada por um movimento que, já no início da década de 2010, dava os seus primeiros passos, na época conhecido como Geração à Rasca, num processo de mimetização daquilo que se passava noutros países, como nos Estados Unidos da América, com os Occupy (Chomsky, 2013), mas sobretudo nos países do sul da Europa, com os Indignados em Espanha (Baumgarten, 2013). O período subsequente foi ainda de alguma agitação e mobilização cívica, tendo como bandeira a crítica às sucessivas medidas de austeridade do governo de Passos Coelho ${ }^{6}$. 0 adensar da contestação nesse período teve a particularidade de acontecer num momento em que os sites de redes sociais já faziam parte do dia a dia de grande parte da população portuguesa e em que proliferavam páginas de movimentos no Facebook. As redes sociais digitais assumiam-se também cada vez mais como plataformas de consumo de notícias (Cardoso et al., 2017, p. 28$)^{7}$ com destaque para o Facebook $(76,7 \%)$ e para o Youtube $(23,7 \%)^{8}$.

O Facebook assume, desse modo, particular relevância no acesso à informação por parte dos cidadãos e em última instância ganha forte protagonismo no que concerne ao diálogo e debate deliberativo. Nesse adverso contexto social e político, vários grupos de cidadãos, com maior ou menor formalidade, organizaram-se, assumindo-se como atores coletivos (Pereira, 2012). Os grupos "Que se Lixe a Troika" e "Indignados Lisboa" são alguns dos que, emanando da sociedade civil, se destacaram nesse período de contestação no contexto português (Figueiras e Espírito Santo, 2016; Figueiras, Espírito Santo e Cunha, 2015) e que fazem parte do grupo de oito movimentos que analisamos neste artigo (para além dos dois referidos, foram considerados os grupos "Democracia e Dívida"; "O Povo é Quem Mais Ordena"; "RiseUp Portugal"; "Artigo 210"; "15 Outubro"; "FLAN Colectivo").

Assim, considerando o pedido de ajuda à Troika como o gatilho que despertou, no contexto português, um conjunto de movimentos cívicos nos sites de redes sociais,

5 Os cálculos são dos organizadores. Disponível em: <https://www.publico.pt/2012/09/28/politica/noticia/os-muitos-numeros-da-manifestacao-de-15-desetembro-em-lisboa-1565022>. Acesso em: 15 ago. 2017. Acrescente-se que ainda existiram mais manifestações um pouco por todas as capitais de distritos entre outras cidades, nesse mesmo dia.

6 A cobertura noticiosa acerca da singular mobilização dos portugueses está disponível em: <https://www.jn.pt/politica/interior/mais-de-um-milhao-de-pessoas-nas-ruas-segundo-o-movimento-quese-lixe-a-troika-3085050.html>. Acesso em: 18 ago. 2017.

7 Disponível em: <https://obercom.pt/praticas-e-consumos-digitais-noticiosos-dos-portugueses-em2016/>. Acesso em: 18 ago. 2017.

8 De acordo com os dados disponibilizados pela plataforma Pordata - Fundação Francisco Manuel dos Santos, o número de indivíduos que acederam à internet pelo menos uma vez por semana cifrava-se nos $58 \%$ em 2013, passando a registar $68 \%$ em 2016, aproximando-se da média da União Europeia numa redução da distância em três pontos percentuais (72\% em 2013 e 79\% entre 2013 e 2016). Disponível em:

<https://www.pordata.pt/Europa/Indiv\%C3\%ADduos+que+acederam+\%C3\%A0+Internet++em+m\%C3 $\%$ A9dia++pelos+menos+uma+vez+por+semana++em+percentagem+do+total+de+indiv\%C3\%ADduos+ por+n\%C3\%ADvel+de+escolaridade+mais+elevado+completo-1488>. Acesso em: 18 ago. 2017. 
procuramos compreender em particular o papel que o Facebook teve enquanto ambiente para a organização e mobilização dos diferentes atores. Nesse sentido, para estudarmos este fenómeno optámos por implementar uma metodologia de tipo misto, que cruza uma abordagem quantitativa (análise de conteúdo das páginas de Facebook dos grupos) com uma dimensão qualitativa (entrevistas a ativistas). Para operacionalizar a investigação, primeiro, estabelecemos como dimensões de observação a análise das circunstâncias em que emergiram os movimentos e a forma como se organizam, ou seja, como é feita a distribuição de papéis internamente; em segundo lugar, verificamos como foi realizado e gerido quer o diálogo, quer a comunicação dentro de cada movimento; depois procuramos compreender como é gerida a interação com os seguidores nas páginas de Facebook; e, finalmente, considerando que o contexto social português mudou depois de 2012 e sobretudo a partir de 2015, com as transformações que levaram à formação histórica do XXI Governo Constitucional Português (David, 2018; Freire, 2017; Galrão e Tavares, 2016), tentamos perceber o papel que as páginas desses movimentos assumem no atual contexto, nomeadamente tendo em conta os novos desafios introduzidos em termos sociais, económicos, políticos e mais recentemente de saúde pública.

Este artigo surge na sequência de um conjunto de estudos que têm procurado analisar em particular a forma como em Espanha e Portugal floresceram um conjunto de movimentos sociais, enquanto resposta à austeridade (Baumgarten e Díez, 2017; Della Porta et al., 2018; Díez, 2017; Fishman, 2011, 2019; Portos e Carvalho, 2019), mas que consideram que existe ainda muito por explorar em relação a estes grupos, nomeadamente no nível da organização e mobilização nos sites de redes sociais (Portos e Carvalho, 2019). Por outro lado, justifica-se também pelo facto de faltarem trabalhos que explorem a ação desses grupos noutros momentos que não aqueles marcados diretamente por crises, ou seja, em que não se verificam triggers particulares que motivem a sua ação.

Em termos de estrutura, na primeira parte do artigo, "Os movimentos sociais e os protestos antiausteridade em Portugal", abordam-se algumas das características dos movimentos sociais em Portugal, salientando-se algumas das particularidades dos protestos antiausteridade e as suas diferenças em relação à mobilização cívica que se registou noutros países. No segundo momento, "Os media sociais e as formas alternativas de participação e mobilização", procura destacar-se a importância que os sites de redes sociais ganharam nas últimas décadas, nomeadamente enquanto espaços que permitem formas alternativas de participação. Nesse contexto, destaca-se a ação dos movimentos e grupos que emergiram nesses espaços, sobretudo nos países do sul da Europa, promovendo ações contra as medidas de austeridade. No terceiro momento, "Desenho da investigação e procedimentos metodológicos", são apresentados os procedimentos metodológicos adotados para a recolha de dados, seja através da análise das páginas de Facebook, seja por meio da realização das entrevistas com membros dos 
grupos. O artigo encerra com a "Apresentação e discussão dos resultados" e as "Considerações finais".

\section{Os movimentos sociais e os protestos antiausteridade em Portugal}

Começamos este artigo por abordar algumas das principais características da mobilização cívica em Portugal. Consideramos que esta contextualização é importante, não apenas tendo em conta os vários estudos que têm comparado a realidade portuguesa com a de outros países do sul da Europa, como, por exemplo, Espanha (Baumgarten e Díez, 2017; Della Porta et al., 2018; Díez, 2017; Fishman, 2011, 2019; Portos e Carvalho, 2019; Nunes, 2019), mas também porque esta caracterização nos pode ajudar a perceber como emergiram os principais protestos antiausteridade no país.

Não é possível falar de mobilização cívica em Portugal sem recordar que o país viveu, durante um largo período, sob ditadura. É apenas com a revolução de 25 de abril de 1974 que se assiste a uma mudança no que ao envolvimento associativo diz respeito. O facto de este ser o marco histórico a partir do qual foram reconhecidas efetivamente liberdades e direitos de cidadania pode ajudar a explicar grande parte do incremento participativo a que se assistiu nos anos seguintes à Revolução dos Cravos (Morais e Sousa, 2012). Os mais de 40 anos de repressão social e política que o país viveu ajudam a perceber o crescimento em termos de envolvimento associativo, mas não devem ser entendidos de forma desligada de outros fenómenos, como a adesão de Portugal, em 1986, à então Comunidade Económica Europeia (CEE).

Se numa abordagem histórica e retrospetiva facilmente conseguimos perceber em que momento se verificou a maior tendência de mobilização cívica no país, importa também lembrar que esta propensão para o envolvimento e a participação nas associações acabaria por se esgotar com alguma rapidez nos anos seguintes à revolução, à medida que os partidos políticos e organizações sindicais se consolidaram. É nesse contexto que podemos compreender o argumento, defendido por alguns autores, de que Portugal apresenta uma sociedade civil fraca (Baumgarten, 2013), procurando quase sempre mostrar a sua insatisfação nos atos eleitorais e menos através de mobilizações cívicas. "Organizações da sociedade civil e movimentos sociais têm sido tradicionalmente fracos e fortemente dependentes de partidos políticos e recursos institucionais para a transformação das suas reivindicações em políticas concretas" (David, 2018, p. 169, tradução própria). No fundo, o que importa realçar é que no país se verificam, após o 25 de abril de 1974, dois processos: se, por um lado, aumentam a atividade política e o sindicalismo, por outro, diminuem as formas tradicionais de envolvimento social voluntário (Barreto, 2004), demonstrando assim que "a participação espontânea não é frequente em Portugal" (Amaral, 2020, p. 3.313), mas também que existe uma considerável institucionalização da mobilização cívica. 
Essas tendências, que os autores entendem como contraditórias, são determinantes para compreender a realidade que o país vive em termos de mobilização cívica, para além de ajudar numa análise dos movimentos que se formaram contra a austeridade. A falta de uma tradição de mobilização espontânea, aliada ao facto de o país não adotar, por norma, modelos informais e não institucionalizados de ativismo social, está na origem de parte dos grupos constituídos no período de intervenção externa. Não podemos, contudo, ignorar que, embora os movimentos que analisamos neste artigo tenham uma base nacional e surjam por isso ligados ao próprio contexto histórico, foram também influenciados pelo cenário internacional (Baumgarten, 2013; Nunes, 2019; Amaral, 2020). Para Tejerina et al. (2013), os protestos contra a austeridade podem mesmo ser analisados no âmbito de um ciclo internacional que teve "várias ondas", surgindo a primeira com a Primavera Árabe e tendo sido a segunda inspirada por esta e despertado nos Estados Unidos com os movimentos de ocupação, e também no sul da Europa com os protestos contra as medidas impostas pela Troika.

Para além dessas diferentes ondas que serviram de inspiração aos movimentos em Portugal, importa ainda lembrar, como refere Baumgarten (2013), que os grupos e mobilizações que emergiram contra a austeridade não apresentam todos as mesmas características, quer em termos de organização, quer em relação ao tipo de participantes, para além de se distinguirem de outras ações de movimentos associativos mais tradicionais. Para a autora, podemos assim considerar que existem três grupos e ações distintas mesmo durante o período de intervenção externa: por um lado, encontramos as ações de grupos associativos mais "clássicos", como os sindicatos, que promovem greves gerais na defesa de direitos específicos; por outro lado, emergiram grupos independentes de cidadãos que se organizaram através de plataformas sociais e promoveram um conjunto de grandes manifestações; e, por fim, a autora refere os movimentos de ocupação dos espaços públicos como um tipo particular de ações espontâneas organizadas por pequenos grupos. Também Nunes (2019), a partir do trabalho de Tejerina et al. (2013), estabelece uma diferença entre movimentos, considerando que aqueles que emergiram no combate à austeridade apresentam características particulares. Assim, ao contrário dos movimentos que apresentam uma identidade de grupo, orientações políticas e ideológicas bem definidas assim como níveis de organização mais institucionalizados e verticais, no período de intervenção externa os movimentos devem ser analisados, defende a autora, considerando as condições sociais dos atores que deles participam, uma vez que estes protestos reuniram cidadãos que se mobilizaram pela primeira vez para uma ação de participação política e cívica (Nunes, 2019).

Nesse sentido, podemos encerrar este primeiro ponto, em que procurámos sobretudo explicar em que contexto emergiram os movimentos que estudamos neste artigo e destacar o que os particulariza, realçando que a profissionalização e a institucionalização dos movimentos mais tradicionais contrastam com a espontaneidade e 
horizontalidade da maioria dos movimentos que lutaram contra as medidas de austeridade. Para além dessas diferenças em termos de organização e ação, que se explicam também pela influência dos media sociais, como veremos no ponto seguinte, a própria natureza dos protestos, apesar de influenciada pelo contexto internacional, assume em Portugal contornos particulares, muito centrados na realidade nacional e no papel do Estado.

Eles têm apenas uma capacidade de mobilização esporádica, exceto quando integrados em órgãos institucionais, como partidos políticos ou sindicatos. A velocidade com que os movimentos mencionados surgiram e se espalharam pelas redes sociais deu-Ihes amplitude e dimensão, mas o seu conteúdo discursivo refere-se a uma realidade nacional muito concreta (a austeridade do momento) e o seu foco era mais local do que global (Silva, 2019, p. 54, tradução própria).

Em Espanha, ao contrário do que aconteceu em Portugal, "os manifestantes antiausteridade espanhóis conseguiram expandir a sua base de mobilização e tornaram-se atores dominantes no campo" (Portos e Carvalho, 2019, p. 5, tradução própria). Em Portugal, a atuação dos grupos acabou também por implicar um esforço de afastamento em relação aos atores institucionais, o que teria consequência, por um lado, em termos de capacidade de mobilização e, por outro, no nível da possibilidade de construção de alianças estratégicas, como se verificou em Espanha.

\section{Os media sociais e as formas alternativas de participação e mobilização}

Depois de, na secção anterior, termos verificado que Portugal apresenta uma fraca tradição em termos de mobilização cívica, terminamos esta abordagem mais histórica destacando como os movimentos que emergiram mais recentemente no país estão sobretudo ligados ao contexto económico interno, ao mesmo tempo que resultam de organizações espontâneas e pouco profissionalizadas. Para compreendermos a forma como estes grupos se organizam, é fundamental observar o papel que os media sociais de um modo geral e os sites de redes sociais em particular assumem neste âmbito.

No ambiente digital contemporâneo, já ninguém tem dúvidas quanto às potencialidades dos media sociais, nomeadamente enquanto meios alternativos para a participação (Dahlgren, 2014). Nas últimas décadas, tem sido evidente o potencial destes espaços, sobretudo em termos comunicativos, uma vez que a facilidade na circulação de informação, aliada ao carácter interativo destes novos meios, faz deles ferramentas únicas que muitos têm sabido utilizar para os mais diversos fins. Os movimentos que se organizam nesses espaços são o principal objeto de análise neste artigo, mas antes de nos debruçarmos sobre a forma como têm aproveitado as potencialidades das ferramentas digitais, importa considerar que existem diferentes tipos de media sociais, e que neste artigo nos concentramos apenas nos sites de redes sociais. Este aspeto é 
importante, na medida em que muitas vezes se confundem as redes sociais com os sites de redes sociais, ignorando desde logo o papel que as pessoas têm neste processo. Raquel Recuero lembra precisamente que, "embora seja senso comum referirmo-nos às ferramentas sociais digitais, tais como Facebook, Twitter, Orkut etc., como "redes sociais", o conceito de rede social não é sinônimo delas" (2017, p. 14). Assim, de acordo com a definição de Boyd e Ellison (2007), uma rede social está sobretudo relacionada com as interações que um grupo estabelece, uma vez que a estrutura que permite estas interações se encontra oculta. Já os sites de redes sociais são sobretudo ferramentas que permitem o estabelecimento de relações ao mesmo tempo que Ihes dão visibilidade. É por isso importante lembrar que "(...) o Facebook, por si só, não apresenta redes sociais. É o modo de apropriação que as pessoas fazem dele que é capaz de desvelar redes que existem ou que estão baseadas em estruturas sociais construídas por estas pessoas" (Recuero, 2017, p. 14).

É importante destacar esta dimensão relacionada com a apropriação, uma vez que não podemos esquecer que são os indivíduos que detêm o poder de utilizar as tecnologias em seu favor e que não se pode por isso acreditar que a internet ou os sites de redes sociais são capazes de melhorar o sistema democrático por si só. Colocar o foco na ação humana é também importante para ultrapassar as posições daqueles que entendem as novas tecnologias e a internet sempre a partir de duas posições: a da "euforia cibernética" ou da "distopia digital" (Correia, 2014, p. 80). Conscientes de que o espaço e as ferramentas digitais não são neutros ou independentes (Correia, 2016; Fuchs e Sandoval, 2014), devemos considerá-los nas suas múltiplas vertentes. Como refere Olsson (2014), a possibilidade de participação no ambiente digital moderno pode ser considerada não apenas como uma "extensão dos interesses corporativos e da lógica capitalista", mas também como "uma nova forma de interação entre consumidores e entre consumidores e marcas", ou ainda como um "recurso para práticas cívicas", tudo depende da forma como se olha para os recursos da comunicação disponibilizados pela web 2.0 (p. 207) e do uso que deles é feito.

No entanto, o aspeto que nos parece mais importante e que importa destacar em termos do potencial das tecnologias digitais está relacionado com o facto de estas reconfigurarem as formas de comunicação com uma considerável inovação em termos do centro de emissão, que deixa de estar centralizado, passando a existir uma alternância das funções de emissão e receção. Esta característica da internet, aliada às possibilidades de utilização, surge assim como uma possibilidade de pluralização dos discursos e um contributo para a sua visibilidade pública.

Há, no entanto, autores, como Figueiras (2017), que consideram sobretudo que é no nível da autonomia dos indivíduos que se produz uma mudança, uma vez que estes passam a poder assumir também o papel de produtores e emissores de conteúdos. Figueiras defende que "a internet abriu as portas do centro nevrálgico do poder dos media - o acesso à produção -, permitindo a qualquer cidadão comum tornar-se um 
emissor em nome individual" (2017, p. 6). A autora entende que esta nova possibilidade dá lugar ao que Manuel Castells define como "autocomunicação de massas" (cf. Castells, 2007, p. 24). Recorrendo a Bruns (2008), Figueiras recupera ainda o termo "produser", para realçar a emergência de uma "figura híbrida", que pode assumir tanto o papel de produtor como de consumidor, mas que, acima de tudo, se distancia do modelo tradicional que se caracterizava por papéis bem definidos e pela centralização da comunicação no nível do emissor. Esta possibilidade constitui a verdadeira novidade introduzida pelas tecnologias digitais, uma vez que, para além de se ampliarem as possibilidades de comunicação, quebram-se as lógicas e os sentidos tradicionais da comunicação. É neste contexto que Coleman argumenta que, "em vez de pensar na internet como uma constelação de engenhosos dispositivos técnicos ou uma massa de conteúdo diferente, poderíamos pensar nela como um novo espaço de articulação pública; uma arena multivocal (...) um espaço potencial de autoexpressão emergente" (Coleman, 2017, p. 87)".

Todo este potencial do ambiente digital, e em particular dos sites de redes sociais, acaba por ganhar maior dimensão e visibilidade no momento de maior questionamento do sistema político por parte dos cidadãos, fruto de uma desconfiança crescente, resultado das crises e da aplicação das medidas de austeridade como resposta às políticas neoliberais (Dahlgren, 2005). É neste contexto que os cidadãos, individualmente ou em grupo, começam a utilizar os sites de redes sociais para se mobilizarem e assim reivindicarem os seus direitos. Para Coleman (2017), "as formas de comunicação social em rede permitiram que os ativistas do século XXI combinassem a coordenação online e a ação nas ruas para definir agendas, influenciar e promover protestos" (p. 17). O autor considera que a amplitude das redes sociais digitais, aliada ao seu carácter inovador e instantaneidade, as torna poderosas ferramentas, pois, "em vez de esperar que os representantes falem por eles, os ativistas digitais aperfeiçoaram práticas dinâmicas de autorrepresentação" (Coleman, 2017, p. 17).

Neste contexto, assiste-se a um afastamento dos partidos tradicionais e ao despertar de novos atores nas redes, que desenvolvem formas distintas de mobilização social e cívica, "porque fundamentalmente reticulares, fluidas e espontâneas - em virtude do papel que nelas assumem as novas tecnologias de informação e comunicação e, cada vez mais, os social media (...)" (Teixeira, 2018, p. 105). Os sites de redes sociais estão assim na base de várias manifestações e movimentos de protesto, como são os casos dos Occupy, nos Estados Unidos da América, mas também em Inglaterra, dos Indignados em Espanha, ou dos vários movimentos que em Portugal surgiram no período de intervenção externa e que analisamos neste artigo.

Apesar de todo o potencial das redes sociais digitais (Figueiras, 2017; Figueiras e Espirito Santo, 2016; Figueiras, Espirito Santo e Cunha, 2015; Dahlgren, 2014), é importante lembrar que não se pode alegar que as revoluções a que assistimos desde a chamada Primavera Árabe, bem como os movimentos de protesto que emergiram na 
sequência da crise económica e financeira de 2008, ficaram a dever ao Twitter ou ao Facebook (Fuchs, 2012, 2014a, 2014b; Fuchs e Sandoval, 2014). Como bem lembra Christian Fuchs, as tecnologias de comunicação não determinam as diferentes lutas que têm sido feitas nas ruas, na medida em que elas são apenas ferramentas que ajudam a que estas lutas tenham lugar. "Enquanto alguns alegaram que houve revoluções no Twitter, no Facebook, outros argumentaram que as revoluções acontecem nas ruas e são feitas por humanos, não por tecnologias (Fuchs, 2012, 2014a)" (Fuchs e Sandoval, 2014, p. 32). Por outro lado, Dahlgren lembra que a motivação para participar é igualmente importante e já tem de fazer parte da identidade dos sujeitos, caso contrário é difícil acreditar na mobilização, mas sobretudo na possibilidade de manutenção e crescimento dos movimentos que venham a ser criados:

Os ativistas não crescem em árvores, obviamente, são produzidos social e discursivamente, e como observado no início, o campo da política alternativa tem aumentado face às crises crescentes. (...) se entendermos a participação como fazendo parte da nossa identidade, os media sociais por si só não farão muito para promovê-la (Dahlgren, 2014, p. 200).

Assim, de um modo geral pode-se dizer que os sites de redes sociais podem ser utilizados pelos cidadãos em diferentes campos: promovendo o mais fácil acesso às instituições políticas; aumentando o volume e o ritmo da informação circulante; diversificando as escolhas em contexto eleitoral; promovendo maior transparência e maior oportunidade de participação na formulação de políticas (Tatagiba, Paterniani e Trindade, 2012). Em suma, podemos estar diante de novas oportunidades para grupos tradicionalmente excluídos e de novos padrões de associação. Não obstante um certo otimismo, ainda que latente, na perspetiva dos referidos autores, não negamos a possibilidade de emergirem formas distintas de associação e cooperação entre os indivíduos com vista à prossecução dos seus interesses individuais e grupais.

Estes atores coletivos de ação política estão inseridos na sociedade em rede através dos intensos e extensos fluxos comunicacionais estabelecidos num modelo multipolar. Com a identificação e a exploração dos elementos constitutivos dos movimentos sociais e das suas ligações à esfera pública digital, não estamos a assumir um determinismo tecnológico como pressuposto, mas sim a fazer um sublinhado sobre as condições de ação e estruturação da atuação destes atores coletivos no espaço público. O que se pretende é identificar e explicar os elementos constitutivos dos movimentos sociais no contexto mais amplo da sociedade em rede, em particular aqueles que dizem respeito aos aspetos comunicacionais, informacionais e interacionais. 0 modelo construído por Castells (2013) ${ }^{9}$ estabelece que esta tipologia de atores tem as

\footnotetext{
$9 \mathrm{Na}$ referida obra o autor identifica no total 11 elementos constitutivos da identidade dos movimentos sociais na sociedade em rede. Apenas vamos considerar quatro no sentido de podermos explorá-los na exposição e discussão teórica da secção seguinte. Os restantes cabem em investigações posteriores,
} 
seguintes caraterísticas: $1^{\circ}$ ) recorrem a um modelo de rede multimodal, através do uso de redes móveis de comunicação por parte dos membros de cada movimento, em particular através do uso das redes sociais como Facebook ou Twitter; $2^{\circ}$ ) a espontaneidade que está na sua origem é elemento central nesta tipologia, brotando dos interstícios inorgânicos da mobilização cívica; 30) a existência de uma ordem ideológica traduzível em causas programáticas que norteiem a ação do movimento; e finalmente, $4^{\circ}$ ) o fomento de uma cultura democrática assente na deliberação, fazendo uso de mecanismos internos de comunicação, mas também de interação com outros atores externos ao movimento. Estas quatro dimensões que caracterizam os movimentos sociais no contexto alargado da sociedade em rede nortearam a operacionalização realizada no contexto da presente pesquisa.

\section{Desenho da investigação e procedimentos metodológicos}

Depois de, na primeira parte do artigo, termos procurado destacar, através de vários contributos teóricos, a importância que, no ambiente digital contemporâneo, os media sociais ganharam, enquanto espaços alternativos para a participação política e mobilização cívica um pouco por todo o mundo, neste segundo momento procuramos apresentar, de forma detalhada, os procedimentos metodológicos que seguimos no desenvolvimento do artigo. Consideramos este ponto particularmente importante, sobretudo tendo em conta que, para alcançarmos os objetivos definidos no início do artigo, optámos por duas técnicas distintas de recolha de dados: a análise de conteúdo e as entrevistas. A pesquisa configura-se assim como de metodologia mista, com articulação entre um momento quantitativo e outro qualitativo. De forma muito sintética dir-se-á que a análise de conteúdo visa compreender como se comunica e se interage nas redes sociais, e em particular nas contas de Facebook dos oito movimentos estudados. Já com a realização das entrevistas presenciais, procura captar-se os significados que os próprios ativistas colocam na sua ação e o que os mobiliza.

Neste ponto procuramos assim apresentar e justificar a seleção de cada uma das técnicas, mas sobretudo explicar como foram aplicadas e que resultados permitiram obter. Mas, antes de nos debruçarmos sobre as técnicas, importa clarificar o período considerado para a análise, bem como os grupos/movimentos selecionados e as suas respetivas páginas de Facebook.

Os grupos/movimentos que mais se destacaram no período de intervenção externa

O panorama ativista português no período de intervenção externa pautou-se por uma grande diversidade e multiplicação de movimentos, contudo apenas alguns

explorados e discutidos com objetivos particulares como, por exemplo, o tipo de organização adotado, que de todo vão além dos da presente reflexão. 
adquiriram maior notoriedade, quer pela visibilidade mediática obtida nos sites de redes sociais, quer através do destaque que Ihes foi dado pelos meios de comunicação tradicionais. Por outro lado, entre os inúmeros movimentos, assistiu-se a uma grande heterogeneidade quanto aos recursos mobilizados para a difusão das suas ações. Para dar guarida a esta grande heterogeneidade, definiu-se a análise de um conjunto de oito movimentos, mediante critérios de visibilidade e meios/recursos mobilizados. Todos os grupos tinham, no momento da análise, presença no Facebook, e nesse sentido o estudo realizado considerou as páginas dos movimentos nessa rede social digital:

Tabela 1

Dados sobre as páginas de Facebook dos movimentos/grupos estudados

\begin{tabular}{|c|c|c|c|c|}
\hline $\begin{array}{l}\text { Nome do } \\
\text { movimento }\end{array}$ & $\begin{array}{c}\text { Ano de } \\
\text { fundação }\end{array}$ & $\begin{array}{l}N^{\circ} \text { de } \\
\text { gostos }\end{array}$ & $\begin{array}{c}N^{\circ} \text { de } \\
\text { seguidores }\end{array}$ & Link \\
\hline 15 Outubro & $12 / 7 / 2011$ & 6.210 & 6.172 & facebook.com/15deOutubro/ \\
\hline Indignados Lisboa & $20 / 7 / 2011$ & 17.951 & 17.950 & facebook.com/IndignadosLisboa/ \\
\hline RiseUp Portugal & $9 / 6 / 2012$ & 136.669 & 135.782 & facebook.com/RiseupPortugal/ \\
\hline FLAN Colectivo & $18 / 6 / 2012$ & 3.037 & 3.051 & facebook.com/flanparatodos/ \\
\hline Que se Lixe a Troika & $27 / 8 / 2012$ & 28.877 & 28.287 & $\begin{array}{l}\text { facebook.com/Que-se-Lixe-a- } \\
\text { Troika-Queremos-as-nossas- } \\
\text { Vidas-177929608998626/ }\end{array}$ \\
\hline $\begin{array}{l}\text { O Povo é Quem Mais } \\
\text { Ordena }\end{array}$ & $10 / 10 / 2012$ & 21.301 & 20.773 & facebook.com/o.povo.ordena/ \\
\hline Democracia e Dívida & $3 / 04 / 2013$ & 1.140 & 1.148 & $\begin{array}{c}\text { https://www.facebook.com/Dem } \\
\text { ocracia-e-D\%C3\%ADvida- } \\
487400131308815 /\end{array}$ \\
\hline Artigo $21^{010}$ & - & - & - & - \\
\hline
\end{tabular}

Fonte: Elaboração própria a partir dos dados das páginas, atualizados em 2/6/2020.

São diversos os movimentos que têm como plataforma publicitária/divulgação para as suas ideias e para a mobilização política e cívica o Facebook, entre os quais se destacam aqueles que apresentamos anteriormente (ver Tabela 1). Com a seleção destas organizações, quisemos essencialmente cobrir um espectro o mais diversificado possível da contestação, nomeadamente considerando o período em análise. Já no que toca à quantidade de movimentos estudados, esta opção foi norteada considerando sobretudo a sua visibilidade no espaço mediático.

Operacionalização da análise de conteúdo das páginas de Facebook

Uma vez conhecidos os grupos, selecionamos e apresentamos alguns dados das respetivas páginas, que iremos explorar mais à frente neste artigo. Neste momento importa sobretudo destacar que a operacionalização feita passou pela conceção e

10 A página de Facebook do grupo "Artigo $21^{0 "}$ deixou de existir na rede social digital e, nesse sentido, não foi possível apresentar dados atualizados em relação ao movimento. 
aplicação de uma grelha que dá corpo à análise de conteúdo das páginas de Facebook dos oito movimentos em estudo. Fazendo uso das palavras de Berelson (1952 apud Vala, 2003, p. 103), a análise de conteúdo pode ser definida como "a descrição objetiva, sistemática e quantitativa do conteúdo manifesto da comunicação". Mais recentemente Krippendorf (1980 apud Vala 2003, p. 103) redefine nos seguintes termos: "uma técnica de investigação que permite fazer inferências, válidas e replicáveis, dos dados para o seu contexto". Considerámos assim que, tendo em conta os objetivos do artigo, a análise de conteúdo se configurava como a técnica que melhor nos podia ajudar a recolher dados que nos permitissem entender o papel que o Facebook teve enquanto ambiente para a organização e a mobilização dos diferentes atores no período em análise, ao longo de uma semana compreendida entre 5 e 11 de junho de 2013.

Definido o período de análise e o corpus a estudar, constituído neste caso pelos grupos/movimentos e as suas páginas de redes sociais, o passo seguinte, após a identificação da técnica de recolha de dados, passou pela sua operacionalização, o que neste caso implicou a definição de dimensões, categorias e unidades de análise.

Para a construção dessa grelha foram consideradas duas dimensões centrais para este artigo: por um lado, as questões relativas à organização e à disseminação da informação, e por outro, os aspetos que dizem respeito ao funcionamento e à organização interna dos grupos, naquilo que considerámos a dinâmica organizativa do debate. Estas dimensões não foram escolhidas de modo aleatório, mas considerando trabalhos anteriores, como o de Carlos (2014), que procurou analisar "quais mudanças os movimentos sociais (...) vivenciaram em decorrência de sua inserção em arranjos participativos, no que concerne às dimensões organizacional, relacional e discursiva da ação coletiva" (p. 451). Neste sentido, as duas dimensões consideradas foram analisadas a partir de cinco indicadores, numa adaptação do modelo inicial desenvolvido por Dader e Cheng (2011) para a análise quantitativa e qualitativa das páginas na web dos partidos políticos em Espanha. Na Tabela 2 são apresentados os cinco indicadores de cada uma das dimensões e o respetivo sistema de pontuações considerado pelos pesquisadores (entre 0 e 6 valores), na avaliação feita do conteúdo apresentado nas páginas de Facebook de cada um dos oito grupos. Importa ainda destacar que os indicadores que compõem cada uma das duas dimensões têm ponderações distintas (entre 1 e 5 valores). Esta opção justifica-se pelo facto de se tratarem de procedimentos que conferem maior complexidade e mobilização de recursos, quer no que toca à organização e à informação, quer em relação à dinâmica organizativa do debate. Assim, o cálculo da ponderação foi feito através da multiplicação dos valores - no mínimo 1, no máximo 5 ao total da pontuação obtida, dando desta forma pesos relativos e distintos a cada um dos indicadores, tendo em conta os diferentes níveis de complexidade referentes à iniciativa cívica e política. Através deste procedimento, conseguimos hierarquizar os cinco indicadores de cada dimensão, atribuindo-Ihes pesos diferenciados, porque na realidade 
envolvem processos complexos, que requerem a mobilização de recursos e níveis de mobilização bem distintos.

Tabela 2

Dimensões, indicadores e pontuações da grelha de análise de conteúdo

\begin{tabular}{|c|c|c|}
\hline Dimensão & Indicadores & Pontuação \\
\hline \multirow{5}{*}{$\begin{array}{l}\text { Organização e } \\
\text { informação }\end{array}$} & Apresentação da organização e sua dinâmica & \multirow{5}{*}{$\begin{array}{c}\text { Nada adequado (0) } \\
\text { Muito pouco adequado (1) } \\
\text { Pouco adequado (2) } \\
\text { Adequado (3) } \\
\text { Bem adequado (4) } \\
\text { Muito adequado (5) } \\
\text { Totalmente adequado (6) }\end{array}$} \\
\hline & Atualidade noticiosa/mediática e política & \\
\hline & Informação de outras organizações e instituições & \\
\hline & Informação de ações da organização & \\
\hline & $\begin{array}{c}\text { Informações que revelem objetivos e orientações } \\
\text { programáticas }\end{array}$ & \\
\hline \multirow{5}{*}{$\begin{array}{l}\text { Dinâmica } \\
\text { organizativa } \\
\text { do debate }\end{array}$} & $\begin{array}{c}\text { Possibilidade de correspondência via postal e/ou outras } \\
\text { plataformas }\end{array}$ & \multirow{5}{*}{$\begin{array}{c}\text { Nada adequado (0) } \\
\text { Muito pouco adequado (1) } \\
\text { Pouco adequado (2) } \\
\text { Adequado (3) } \\
\text { Bem adequado (4) } \\
\text { Muito adequado (5) } \\
\text { Totalmente adequado (6) }\end{array}$} \\
\hline & Bloco de notas & \\
\hline & $\begin{array}{c}\text { Complexidade do enquadramento dos posts da } \\
\text { administração }\end{array}$ & \\
\hline & $\begin{array}{l}\text { Existência de comentários na própria página aos seus } \\
\text { posts e aos dos seguidores }\end{array}$ & \\
\hline & Correspondência por mensagem privada & \\
\hline
\end{tabular}

Fonte: Elaboração própria com base na revisão teórica realizada.

Depois de apresentarmos as dimensões e os indicadores, neste ponto vamos também procurar, de forma sucinta, explicar os aspetos que se procuram abordar em cada um, facilitando desta forma a posterior interpretação dos resultados obtidos.

Assim, na primeira dimensão, procurou abordar-se o conjunto de estratégias visado pela organização para, em última análise, obter a mobilização dos seus seguidores. Todavia, a montante deste processo, encontra-se a promoção e a divulgação da informação, bem como os aspetos organizacionais e programáticos que presidem à fundação e à ação concreta. Neste contexto, no primeiro indicador, "Apresentação da organização e sua dinâmica", analisou-se a existência de informação acessível, no que toca à orgânica interna e possível distribuição de responsabilidade no interior da organização, considerando em particular: a identificação dos cargos; a definição e a apresentação dos objetivos; os aspetos históricos que levaram à fundação da organização. No segundo indicador, "Atualidade noticiosa/mediática e política", analisaram-se sobretudo a diversidade e a atualidade das fontes noticiosas utilizadas pelas organizações, confrontando a data da notícia e a data da sua publicação. No terceiro ponto, "Informação de outras organizações e instituições", consideraram-se, em face da grande multiplicação e diversidade de grupos presentes no Facebook, os que têm como grande alvo a luta e a contestação em relação às políticas de austeridade, e a possibilidade de colaboração entre esses movimentos. Analisaram-se assim a existência de comentários de outras organizações; o acesso à informação de eventos organizados por outros movimentos; à partilha de ligações com conteúdos de outras organizações. No 
indicador "Informação de ações da organização", procurou-se avaliar a diversidade, ou ausência desta, na publicitação das ações levadas a cabo. Registou-se assim a existência de posts, de vídeos, mas também de fotografias de promoção das diferentes ações. No quinto e último indicador, "Informações que revelem objetivos e orientações programáticas", avaliou-se a possibilidade de aceder aos conteúdos programáticos dos grupos, nomeadamente considerando a sua presença na identificação da página da organização, na janela de eventos ou na imagem de capa e/ou perfil.

Já na segunda dimensão, relativa à "Dinâmica organizativa do debate", procurámos avaliar um conjunto de aspetos relacionados com o funcionamento interno dos grupos, não apenas em termos de comunicação entre os membros do grupo, mas também com os seguidores. Assim, no primeiro indicador, "Possibilidade de correspondência via postal e/ou outras plataformas", avaliou-se a existência de canais diversificados de comunicação, para além do Facebook, que permitam aos atores trocar informação e participar política e civicamente. Neste sentido, registou-se a existência de um e-mail, de um endereço postal, mas também de um blogue ou site afeto à organização. No indicador "Bloco de notas", procuramos perceber a importância particular deste espaço para a exposição e discussão programática da organização. Assim, o indicador foi operacionalizado através do registo quanto à existência ou ausência deste espaço de diálogo e troca de informação, a existência de notas recentes, bem como de comentários da própria administração da página. No terceiro indicador, "Complexidade do enquadramento dos posts da administração", avaliaram-se a profundidade e o tratamento dos posts realizados, procurando perceber, em particular, o seu enquadramento, bem como os argumentos apresentados. No indicador "Existência de comentários da própria página aos seus posts e dos seguidores", avaliou-se de certo modo a reciprocidade, ou seja, se os posts contam com comentários de seguidores, bem como se estes comentários têm, por sua vez, respostas. No último indicador, "Correspondência por mensagem privada", testamos a capacidade de resposta dos grupos ao envio de mensagens privadas através das páginas do Facebook, um aspeto importante para perceber também a importância da ligação com os seguidores das páginas (ver Tabela XVII no Anexo I).

Com esta apresentação sucinta dos indicadores acreditamos que ficam mais claros os aspetos que procurámos estudar em cada uma das duas grandes dimensões que orientaram o artigo. No ponto seguinte, concentramo-nos na apresentação da segunda técnica de recolha de dados utilizada: as entrevistas presenciais.

Procedimentos para a realização de entrevistas presenciais com os ativistas

A análise de conteúdo é central neste artigo, mas a interpretação e a compreensão dos dados que esta técnica permitiu recolher ganharam mais sentido através das respostas obtidas com as entrevistas realizadas. A escolha das entrevistas 
presenciais semiestruturadas (Berger, 2016) surge com o objetivo de permitir a recolha de dados acerca do significado que os próprios atores, no caso, membros dos movimentos e das páginas estudadas, colocam na ação ativista, em contexto real, mas sobretudo no que reveste a utilização do Facebook. As entrevistas permitem assim que o indivíduo responda "(...) de forma exaustiva, com as suas próprias palavras e através do seu próprio quadro de referência, a uma questão geral (o tema) pela ambiguidade" (Ghiglione e Matalon, 2001, p. 87). O recurso às entrevistas, no presente artigo, surge assim como forma de verificação e aprofundamento, uma vez que se procuram coletar dados não apenas baseados nas impressões e perceções dos entrevistados, mas também factos e dados concretos, como, por exemplo, o número efetivo de membros de cada movimento. Por outro lado, a realização da entrevista presencial pretende discernir o seu enquadramento sociológico, bem como a linguagem corporal implicada (Croucher e Cronn-Mills, 2015). Assim, foram realizadas seis entrevistas presenciais ${ }^{11}$ tendo por base um amplo guião ${ }^{12}$, que percorre as duas dimensões em análise, mas também outras vertentes que não foram consideradas neste artigo ${ }^{13}$. No primeiro grupo de questões, solicita-se ao entrevistado que ajude os investigadores a compreender como funciona o grupo de que faz parte em termos de organização interna e disseminação de informação. Já no segundo grupo de perguntas, pretende-se recolher dados que permitam um retrato da perceção do entrevistado, do modo como é realizada e até dinamizada a comunicação interna, mas especialmente do modo como os ativistas percecionam a efetiva mobilização dos seus seguidores, em contexto digital e posteriormente em contexto real.

Todas as entrevistas foram realizadas em espaços públicos, na cidade de Lisboa, e sob garantia de anonimato. As questões colocadas e as respostas obtidas foram gravadas, para efeitos de transcrição e posterior análise, que assumiu neste artigo uma lógica sobretudo descritiva e interpretativa, ou seja, não se procurou nem uma categorização, nem uma quantificação das ideias apresentadas nas respostas. Procurámos, acima de tudo, não desvirtuar as opiniões de cada um dos ativistas entrevistados, dando-lhes, para este efeito, a palavra.

Os elementos dos grupos foram contactados todos no mesmo dia, tendo em vista o agendamento das entrevistas, sendo que estas acabariam por ser realizadas em função da disponibilidade demonstrada em dias e locais distintos (ver Tabela 3). As entrevistas tiveram, em média, 59 minutos, sendo a entrevista ao movimento "RiseUp Portugal" a que apresenta maior duração, pelo facto de ter sido realizada a dois dos ativistas do

\footnotetext{
11 Embora estivessem previstas inicialmente oito entrevistas presenciais, depois de várias e reiteradas tentativas, não foi possível obter entrevista de ativistas do "Artigo 210" e "FLAN Colectivo".

12 Ver Anexo II.

13 Os dados apresentados neste artigo resultam de uma seleção feita a partir de um conjunto maior de dados, obtidos tendo em vista o desenvolvimento de um trabalho de mestrado em sociologia (Sousa, 2013): programa de estudo "Exclusões e políticas sociais", na Faculdade de Ciências Sociais e Humanas da Universidade da Beira Interior, na Covilhã, Portugal.
} 
grupo. No total foram realizados 350 minutos (pouco abaixo das seis horas) de entrevista, que foram integralmente transcritos.

Tabela 3

Agendamento, realização e duração das entrevistas

\begin{tabular}{|l|c|c|c|}
\hline Organização & Agendamento & Realização da entrevista & Duração \\
\hline Que se Lixe a Troika & $10 \mathrm{~h} 2918$ julho 2013 & $14 \mathrm{~h} 30-20$ agosto 2013 (Anjos) & $54 \mathrm{~h} 21 \mathrm{~min}$ \\
\hline Indignados Lisboa & $10 \mathrm{~h} 3018$ julho 2013 & $17 \mathrm{~h} 30-20$ agosto 2013 (Caís do Sodré) & $53 \mathrm{~h} 52 \mathrm{~min}$ \\
\hline Democracia e Dívida & $10 \mathrm{~h} 3118$ julho 2013 & $14 \mathrm{~h} 15-2$ agosto 2013 (Gulbenkian) & $50 \mathrm{~h} 05 \mathrm{~min}$ \\
\hline $\begin{array}{l}\text { O Povo é Quem Mais } \\
\text { Ordena }\end{array}$ & $10 \mathrm{~h} 3218$ julho 2013 & $14 \mathrm{~h} 30-30$ julho 2013 (Campo de Ourique) & $28 \mathrm{~h} 34 \mathrm{~min}$ \\
\hline RiseUp Portugal & $10 \mathrm{~h} 3318$ julho 2013 & $16 \mathrm{~h} 00-29$ julho 2013 (Rossio) & $53 \mathrm{~h} 22 \mathrm{~min}$ \\
\hline Artigo 210 & $10 \mathrm{~h} 3318$ julho 2013 & - & - \\
\hline 15 Outubro & $10 \mathrm{~h} 3518$ julho 2013 & $13 \mathrm{~h} 10-6$ setembro 2013 (FCSH-Nova) & $51 \mathrm{~h} 04 \mathrm{~min}$ \\
\hline FLAN Colectivo & $10 \mathrm{~h} 3518$ julho 2013 & - & - \\
\hline
\end{tabular}

Fonte: Elaboração própria com base no trabalho desenvolvido.

Para encerrar esta segunda parte do artigo, dedicada a apresentar o desenho da investigação e os procedimentos metodológicos, expomos, de forma sucinta, uma breve caracterização dos entrevistados, que pode ajudar na posterior interpretação das respostas dadas e que serão expostas no ponto seguinte:

Tabela 4

Caracterização social e demográfica dos entrevistados

\begin{tabular}{|l|c|c|c|c|}
\hline Organização & Género & Idade & Escolaridade & $\begin{array}{c}\text { Ocupação } \\
\text { Profissional }\end{array}$ \\
\hline $\begin{array}{l}\text { Que se Lixe a } \\
\text { Troika }\end{array}$ & Feminino & 29 & Licenciatura & Jornalista \\
\hline $\begin{array}{l}\text { Indignados } \\
\text { Lisboa }\end{array}$ & Feminino & 48 & Licenciatura & Desempregada \\
\hline $\begin{array}{l}\text { Democracia e } \\
\text { Dívida }\end{array}$ & Masculino & 66 & Licenciatura & Reformado \\
\hline $\begin{array}{l}\text { O Povo é Quem } \\
\text { Mais Ordena }\end{array}$ & Feminino & 31 & 120 ano & Desempregada \\
\hline $\begin{array}{l}\text { RiseUp } \\
\text { Portugal 1 }\end{array}$ & Masculino & 38 & 120 ano & Desempregado \\
\hline $\begin{array}{l}\text { RiseUp } \\
\text { Portugal 2 }\end{array}$ & Masculino & - & Mestrado & Desempregado \\
\hline 15 Outubro & Masculino & 34 & Gestor \\
\hline
\end{tabular}

Fonte: Elaboração própria com base nos dados recolhidos.

Os dados da Tabela 4 permitem-nos verificar que a maioria, quatro em sete dos entrevistados, é do género masculino. A média de idade dos entrevistados situa-se nos 41 anos. Em termos profissionais, existem situações bastante distintas na medida em que entre os entrevistados existem desempregados, mas também gestores, jornalistas e 
aposentados. Encerramos assim este segundo ponto para, de seguida, passarmos à apresentação dos principais resultados, procurando articular os dados obtidos através da análise de conteúdo, com as respostas que consideramos mais relevantes e que nos foram dadas pelos ativistas entrevistados.

\section{Apresentação e discussão dos resultados}

Neste ponto apresentamos os principais resultados coletados através da aplicação das duas técnicas de recolha de dados: a análise de conteúdo e as entrevistas. Antes de passarmos aos resultados propriamente ditos, importa lembrar que o período considerado para a análise das páginas do Facebook dos movimentos teve início a 5 de junho de 2013 e encerrou a 11 de junho de 2013, ou seja, foi considerada uma semana da atividade destes movimentos, que ganharam maior visibilidade durante o período de intervenção externa no país. Durante o período analisado, consideraram-se vários aspetos, como explicámos no ponto anterior em cada um dos indicadores, destacando-se necessariamente os posts publicados em cada uma das páginas. No total, foram analisados 88 posts, destacando-se a publicação, no intervalo considerado, das páginas "15 Outubro" (22 posts), "Indignados Lisboa" (17), "RiseUp Portugal" (16) e "Democracia e Dívida" (14):

Tabela 5

Número de posts analisados entre 5 e 11 de junho de 2013

\begin{tabular}{|l|c|}
\hline Nome do movimento & No de post analisados \\
\hline 15 Outubro & 22 \\
\hline Indignados Lisboa & 17 \\
\hline RiseUp Portugal & 16 \\
\hline FLAN Colectivo & 8 \\
\hline Que se Lixe a Troika & 5 \\
\hline $\begin{array}{l}\text { O Povo é Quem Mais } \\
\text { Ordena }\end{array}$ & 6 \\
\hline Democracia e Dívida & 14 \\
\hline Artigo 210 & - \\
\hline
\end{tabular}

Fonte: Elaboração própria com base nos dados recolhidos.

Centrando a nossa atenção na operacionalização realizada, e que passou pela atribuição de uma pontuação a cada um dos indicadores analisados, como explicamos anteriormente, podemos verificar, numa análise geral ao desempenho dos diversos movimentos em estudo, que o "RiseUp Portugal" é o movimento que obtém melhor pontuação, ao alcançar 140 pontos (ver Gráfico 1), seguindo-se o "Democracia e Dívida" e o "15 Outubro", ambos com 134 pontos. O "Que se Lixe a Troika" revela uma posição que fica aquém do seu protagonismo mediático, sobretudo se considerarmos o seu papel na organização das grandes mobilizações de 15 de setembro. 


\section{Gráfico 1}

Pontuações totais dos movimentos nas duas dimensões analisadas

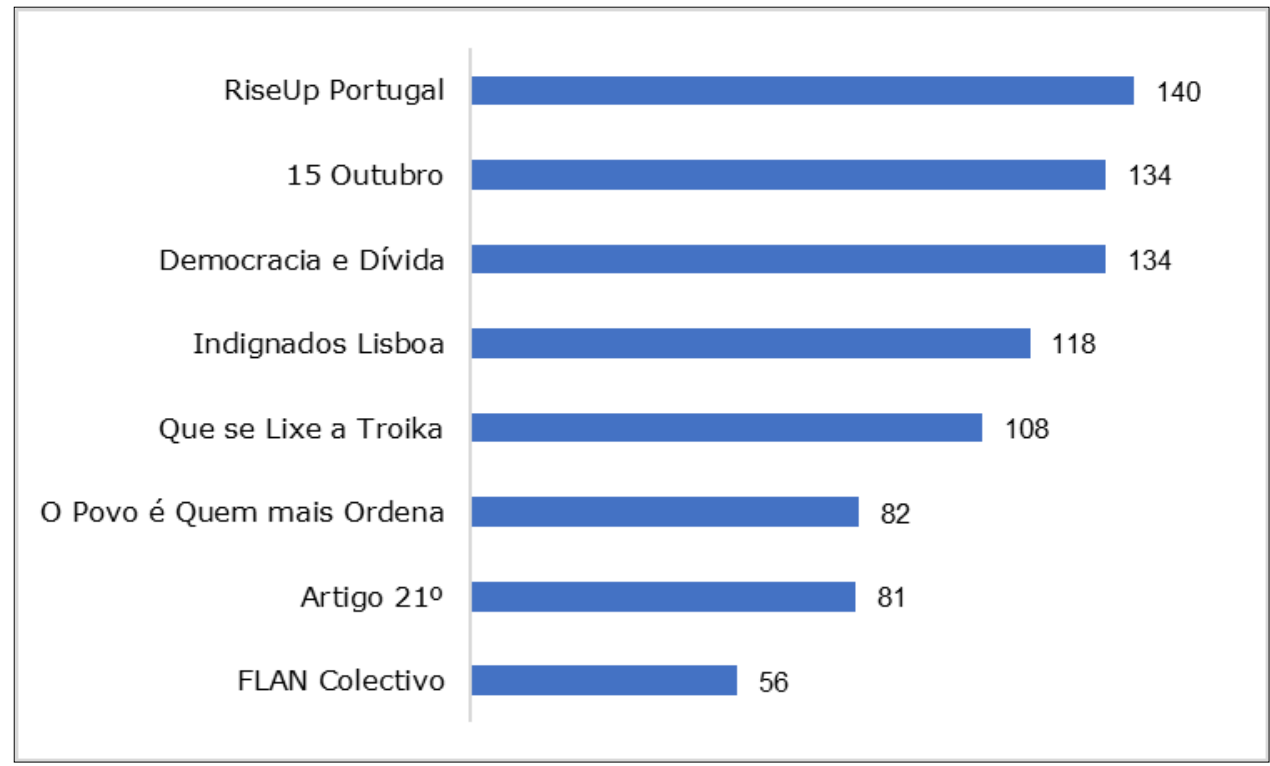

Fonte: Elaboração própria com base na análise de conteúdo às páginas dos oito movimentos.

Como observámos, a ação dos movimentos sociais pode ser presidida por um plano programático e organizacional. Na dimensão "Organização e Informação" (ver Gráfico 2), procurava-se, entre as páginas dos diferentes movimentos, informações alusivas à sua apresentação, dos seus elementos e, num patamar de maior sofisticação, uma dada ordem programática. 
Gráfico 2

Organização e informação

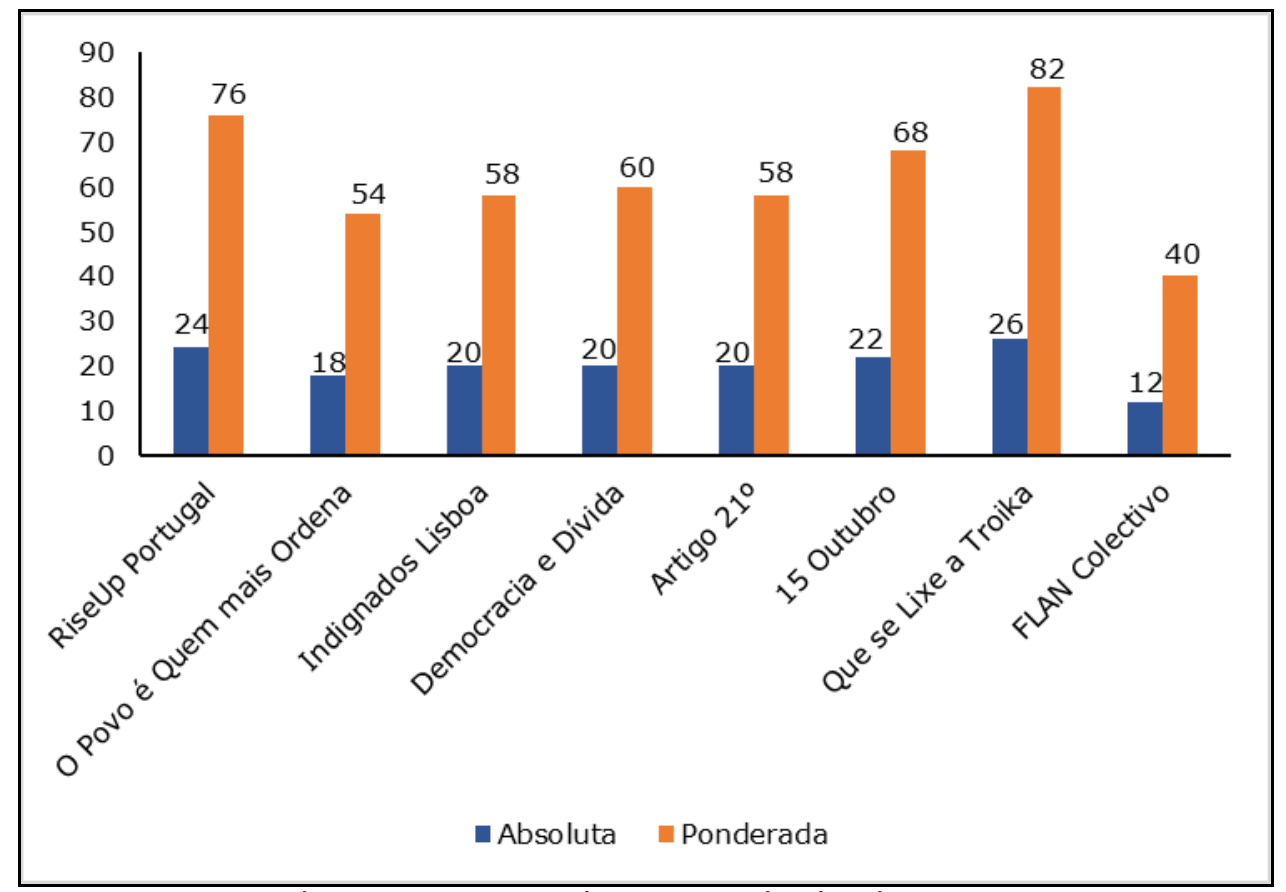

Fonte: Elaboração própria com base na análise de conteúdo às páginas dos oito movimentos.

Através dos dados (Gráfico 2 ) $^{14}$, podemos considerar, em geral, que existem três patamares de desempenho nesta dimensão. Num primeiro, encontram-se o "Que se Lixe a Troika" e o "RiseUp Portugal", num segundo patamar, cinco movimentos com pontuações intermédias e, finalmente, o "FLAN Colectivo". Se, por um lado, o movimento "Que se Lixe a Troika" obtém, em quase todos os cinco indicadores, pontuação máxima, o "RiseUp Portugal" tem pontuação máxima nos indicadores intermédios, que dizem respeito a partilha e troca de informações. Apenas o "Que se Lixe a Troika" e o "O Povo é Quem mais Ordena" registam valores máximos no quinto indicador, que operacionaliza a existência e a apresentação de uma ordem programática.

Considerando as pontuações absolutas, e atendendo que a amplitude pode ir de 0 a 30 pontos, verificamos que é o movimento "Que se Lixe a Troika" a obter o registo mais elevado (26 pontos), seguido do "Rise Up Portugal", com 24 pontos, e os 22 do "15 Outubro". Em antagonismo, temos o "FLAN Colectivo", com 12 pontos, e o "Democracia e Dívida" e "Indignados Lisboa", com 20 respetivamente. Apenas dois movimentos obtêm 6 pontos no indicador relativo à clareza na definição de objetivos, trata-se do "O Povo é Quem mais Ordena" e do "Que se Lixe a Troika". No que concerne ao indicador que

14 Ver pontuação completa nas tabelas do Anexo I. 
avalia a apresentação do movimento, apenas o "O Povo é Quem mais Ordena" atinge valor máximo. O "RiseUp Portugal" e o "Artigo 210" ficam-se apenas por dois pontos.

Contudo, as entrevistas são mais explicitas no que diz respeito às origens dos movimentos. Podemos tipificar este momento de dois modos. Um modo espontâneo e de natureza individual, apresentado da seguinte forma:

É assim, nós primeiro não somos propriamente uma Organização. E a história, se calhar, começa pelo meu perfil. Há um dia no café que eu estou a ver notícias, são aquelas notícias que nós vemos todos os dias e saiu-me alguns comentários que são aqueles comentários depreciativos, que todos nós fazemos de certo tipo de notícias. Comentários depreciativos à sociedade em que estamos neste momento inseridos ao estarmos aqui e não estarmos noutro lado. E esses comentários saíram-me ah e foram imediatamente copiados por um filho meu. Ou seja, eu estava a passar uma carga enorme de negativismo à criança. $E$ isto deu-me um clique, porque eu aprendo um bocado com ele (RiseUp Portugal).

O segundo modo de origem dos movimentos, de natureza coletiva, é expresso na seguinte resposta:

Os Indignados de Lisboa surgiram com esse nome embora as pessoas antes do nome já se reunissem e já falassem de política, já participassem naquilo que havia, manifestações, protestos. Surgiu depois ou durante a Acampada do Rossio (Indignados Lisboa).

Em síntese, pode considerar-se que existem duas tipologias no que concerne à emergência dos diferentes movimentos sociais aqui considerados: o grupo daqueles que surgiram da iniciativa de um ou dois indivíduos e que acentuam muito a relevância dos dispositivos de comunicação como os sites de redes sociais, de que é exemplo o Facebook, encontrando-se neste grupo movimentos como o "RiseUp Portugal" e o "O Povo é Quem Mais Ordena"; um segundo conjunto de movimentos, como são os casos do "Indignados Lisboa" ou do "Democracia e Dívida", que emergiram em resultado de movimentações e mobilização de algumas dezenas de atores individuais, que já mantinham alguma ligação, fazendo uso de recursos digitais, mas sobretudo em copresença.

Contudo, e de acordo com os vários testemunhos recolhidos, todos tiveram como propulsor inicial a reação ao conjunto de circunstâncias económicas e políticas que resultaram numa substancial degradação das condições económicas, políticas e de vida da população em geral no contexto da intervenção da Troika.

A segunda dimensão (ver Gráfico 3) a considerar na presente reflexão versa sobre a dinâmica organizativa do debate interno. No fundo, pretendeu-se perceber como decorre o debate de ideias e como são planeados os eventos e as ações levadas a cabo pelo movimento, e ainda quais instrumentos são utilizados para tal. Desta forma 
pensamos vir a compreender os processos deliberativos que estão a montante das diversas iniciativas levadas a cabo pelos diferentes movimentos.

Gráfico 3

Dinâmica organizativa do debate

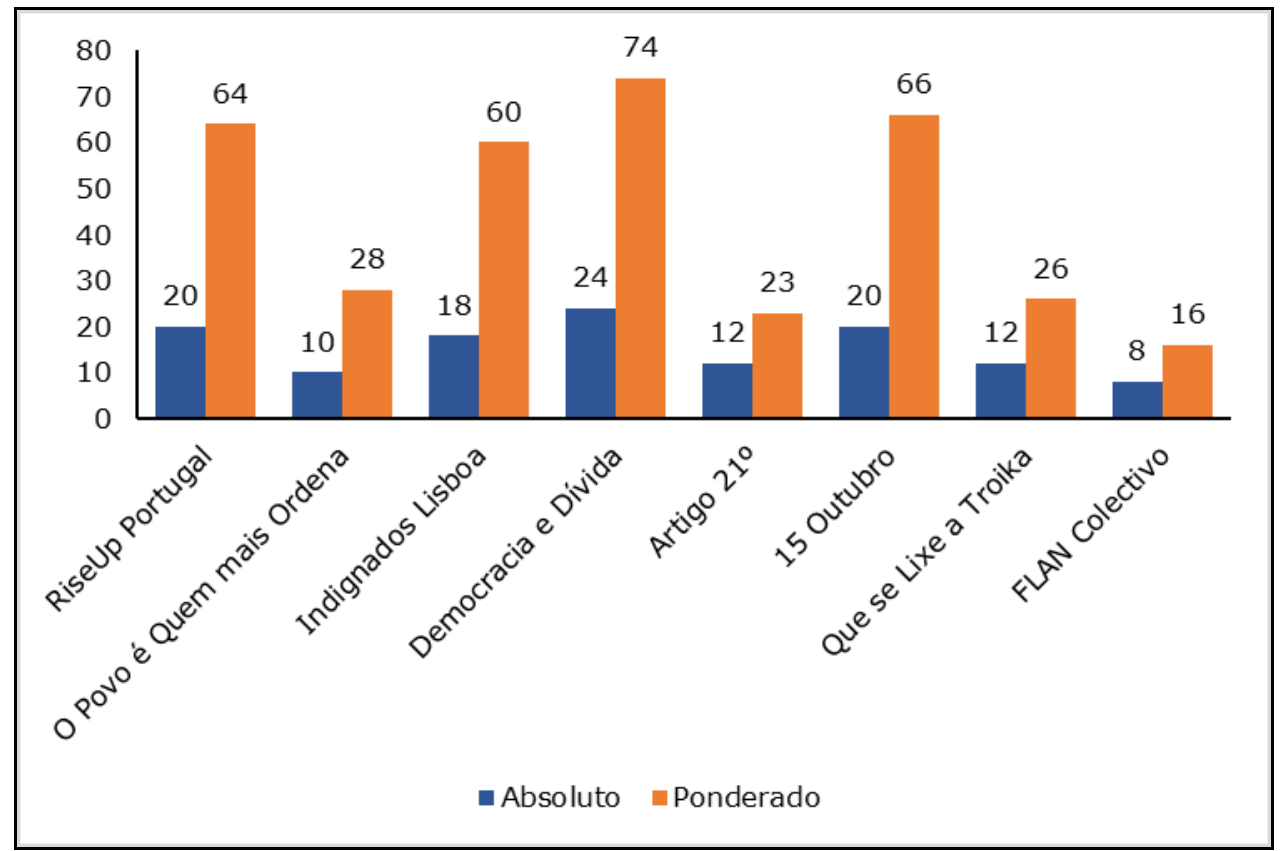

Fonte: Elaboração própria com base análise de conteúdo às páginas dos oito movimentos sociais.

Não existe qualquer movimento que obtenha a pontuação máxima de seis pontos no indicador relativo à possibilidade de correspondência. O que se observa é que os movimentos estão presentes noutras plataformas, como por exemplo blogues, porém o mesmo não se pode dizer no que respeita ao tradicional endereço postal.

O "Bloco de notas" (entretanto alterado na arquitetura do Facebook para "Notas") é um espaço que convida a um diálogo mais intimista entre os participantes do movimento, uma vez que só é acessível aos administradores da conta e aos seguidores da mesma. Neste espaço os ativistas podem inserir conteúdos, cabendo aos seguidores a possibilidade de comentar. Apenas o "Democracia e Dívida" obtém pontuação máxima neste ponto, uma vez que faz uso e atualiza o espaço com, por exemplo, apelos à mobilização. Nos restantes movimentos, o recurso a esta ferramenta é escasso ou inexistente.

Existe, em geral, um grande investimento por parte dos diversos movimentos no modo como levam a cabo o enquadramento dos conteúdos partilhados no Facebook. A exceção é mesmo o "Que se Lixe a Troika", que regista 2 pontos, o que não deixa de representar um indício de uma dada estratégia, sobretudo pelo facto de se tratar de um movimento mais institucionalizado, na medida em que apresenta ordem programática 
bem definida, tem um conjunto fixo e alargado de ativistas, bem como um responsável específico pela comunicação com os restantes atores mediáticos e institucionais, entre os quais partidos políticos e sindicatos.

Sobre os traços que distinguem o "Que se Lixe a Troika" relativamente aos restantes movimentos objeto de estudo, são vários os ativistas de outros movimentos, como os do "Democracia e Dívida", do "RiseUp Portugal" ou do "O Povo é Quem mais Ordena", que procedem, em nível discursivo, a um claro afastamento dos seus respetivos movimentos relativamente ao "Que se Lixe a Troika", acusando este último de ser fortemente partidarizado por forças políticas com assento parlamentar.

Em geral os registos obtidos pelos oito movimentos no indicador relativo à existência de comentários são baixos. O valor mais elevado é o do "Democracia e Dívida", que regista quatro pontos. Todos os restantes distribuem-se entre os 2 pontos e até mesmo 0 ponto. Os dados revelam assim baixa interação e comunicação dos ativistas com os seguidores do respetivo movimento no Facebook. Estes dados são ainda mais indiciadores, quando comparados com os do indicador que operacionaliza a troca de mensagens da página de cada movimento com um seguidor que pede informação sobre eventos ou ações de protesto a realizar (indicador 2.5 ver Tabela XVII do Anexo I) ${ }^{15}$. Ainda assim são cinco os casos em que houve resposta. Estes dados comparados com o número de entrevistas realizadas (seis) pela equipa de investigação são relevantes, sobretudo considerando o caso de "O Povo é Quem mais Ordena", que optou por não responder sobre ações de protesto no curto prazo, mas acedeu, ainda assim, à realização da entrevista.

Ao longo das seis entrevistas presenciais foi possível perceber que existe um uso intermitente de diferentes ferramentas que permitem a comunicação e a interação entre os membros dos movimentos sociais em estudo: para além do Facebook, o " $\mathrm{N}-1$ ", que é uma ferramenta criada por ativistas e para ativistas políticos e sociais, e ainda a mailing list. As diatribes e vicissitudes destas ferramentas são descritas nos seguintes termos:

Depois, voltou-se ao formato mailing list. Que é um formato que é utilizado pela maior parte dos grupos. E é um formato que eu não tenho problema nenhum em caraterizar como o "cancro dos movimentos sociais". O formato mailing list, porque produz muito lixo, tem organização muito dispersa, é muito tentador, as pessoas reagirem a emails, porque têm sempre aquilo aberto. Portanto, acabam por criar muitos atritos, muitas vezes, porque a comunicação online tem muita coisa em que peca, comparativamente à parte presencial. Porque depois fica-se com aquela ideia, se não tem lá um smile, já pensa que está zangado (Que se Lixe a Troika).

15 O envio da mensagem ficou a cargo de um dos investigadores, a partir da sua conta pessoal no Facebook. O outro investigador abordou os oito movimentos, também por mensagem, para a realização da entrevista presencial. 
JOÃO CARLOS SOUSA; RICARDO MORAIS

Nesta mesma linha, importa realçar um outro testemunho que relativiza o papel do Facebook na comunicação entre os membros do movimento, frisando o papel potencialmente difusor que esta rede social tem na disseminação de conteúdos informativos:

Epah, o Facebook é uma coisa porreira para em termos da reação imediata, por um lado e é mais viral. Eu, sempre que faço um texto, ponho-o no Facebook e depois há todos aqueles grupos onde me puseram e depois vou, partilho, partilho. E é engraçado porque depois vou ver na contagem de "gajos" que foram ver no blog, é engraçadíssimo ver passado um bocado aquilo "pim-pim-pim" de pessoal que vai ver uma coisa que é interessante. No email eu faço essa contagem, mas é depois, posteriormente (Democracia e Dívida).

O Facebook é, deste modo, percecionado com algumas reservas. Por outras palavras, o que transborda do discurso do ativista do "Democracia e Dívida" é a experiência de uso do Facebook como ferramenta de difusão e divulgação de conteúdos informativos. Fica implícita a ideia de uma certa linearidade na apropriação do Facebook no sentido vertical - de ativistas para os respetivos seguidores.

\section{Uma mobilização cívica limitada no tempo e refém de triggers}

Depois de termos apresentado os dados relativos à forma como emergiram os grupos estudados neste artigo, mas sobretudo em relação ao modo como se organizaram e comunicaram num período de tempo particular, procuramos, numa tentativa de mostrar a importância de continuar a estudar a ação destes movimentos, apresentar alguns dados mais recentes sobre a sua atividade. Esta necessidade de voltar a olhar para as páginas prende-se não apenas com o facto de o contexto social português ter mudado - mudou depois de 2013 e sobretudo a partir de 2015, com as transformações que levaram à formação do XXI Governo Constitucional Português - mas também porque nos permite avaliar a possibilidade de estarmos apenas perante grupos de mobilização limitada e, de certa forma, superficial.

Assim, no seguimento do que verificámos no primeiro ponto deste artigo, o tipo de mobilização cívica que se verificou em Portugal, nomeadamente no período de intervenção externa, esteve sobretudo ligado a um momento particular, no caso, a intervenção da Troika. Com este dado, o que procuramos realçar é o facto de que em Portugal se verifica uma tendência de mobilização localizada e delimitada, ou seja, o tipo de movimentos e grupos que surge nas redes sociais tem normalmente dificuldades em manter a sua atividade quando não existem triggers particulares que justifiquem a sua ação. Por outro lado, ao contrário do que aconteceu noutros países, como, por exemplo em Espanha, no caso português, os grupos de protesto que emergiram contra a intervenção externa não estiveram na origem de novos partidos e não conseguiram 
também manter a sua atividade cívica, pelo menos em termos de mobilização, quer online, quer na organização de novos protestos.

Para confirmarmos esta ideia, observámos a ação mais recente das páginas dos movimentos estudados. O primeiro aspeto que verificámos prende-se com o facto de a página do grupo "Artigo 210" já não existir. Quanto às páginas de Facebook dos restantes grupos, percebemos que são poucas as que mantêm uma atividade regular, ou seja, poucas se mantêm atualizadas.

A página do grupo "RiseUp Portugal" é uma das que continua a publicar posts diariamente, para além de ser também uma das que faz, quase sempre, um enquadramento dos conteúdos partilhados. Entre as partilhas, destacam-se notícias de meios de comunicação, mas também memes, conteúdos de outras páginas da rede social digital e ainda alguns conteúdos próprios. Importa também realçar que os conteúdos produzidos e partilhados apresentam sempre um tom de denúncia de grupos e atores considerados privilegiados. Entre as principais temáticas abordadas, destacam-se: promiscuidade entre elites políticas e financeiras; corrupção; denúncia de problemas/questões ambientais; chamadas de atenção e denúncias para a manipulação feita pelos media tradicionais em relação a determinados assuntos; e, mais recentemente, alertas para os abusos laborais cometidos tendo em conta a situação de pandemia provocada pela Covid-19. A página continua a identificar um ativista como o principal gestor, ao qual se juntam outros elementos, num total de oito, oriundos de diferentes países (cinco de Portugal e um de cada um dos seguintes países: Alemanha, Irlanda e Ucrânia).

Já a página do "Que se Lixe a Troika", movimento que assumiu um papel mais determinante na organização das grandes mobilizações de 15 de setembro, apresentase, na consulta realizada a 27 de maio de 2020, algo desatualizada ou, dito de outra forma, regista uma falta de periodicidade no nível das publicações. Assim, a última publicação da página data do início de maio (foi realizada no dia 3 ) e diz respeito à realização de um debate sob o mote "Será o coronavírus a crise final do capitalismo?". A publicação seguinte remonta a 14 de março de 2020 e, fazendo uso de um vídeo, associa o coronavírus à crise climática. Verificámos ainda que no ano de 2020 foram realizadas apenas três publicações nesta página. Na página, continua a não ser identificado um gestor público, mas no total são 13 os elementos que gerem o seu conteúdo (12 de Portugal e 1 do Luxemburgo).

A página do grupo "O Povo é Quem Mais Ordena" também se encontra de certo modo desatualizada. A última publicação data de 30 de abril de 2020, verificando-se também que as publicações feitas até esta data são bastante irregulares. Assim, conseguimos encontrar numa semana várias publicações, a que se seguem períodos de ausência de posts. Em termos de conteúdo, as publicações deixaram de assentar numa mensagem explicitamente política, nomeadamente através de caricaturas, para passarem a ser, na maioria dos casos, memes com apenas texto em fundo a cores, sobre 
diversas temáticas. Ao contrário do que acontece noutras páginas, a situação do coronavírus não é central na discussão promovida na página, mas, quando aparece, é quase sempre enquadrada em termos das implicações políticas e económicas para o país. Em termos de gestão, a página é gerida por dois perfis com conta na rede social digital.

Uma das páginas mais desatualizadas, para não dizer inativa, é a do grupo "15 Outubro". A última postagem data de 5 de julho de 2017. Apesar de continuar a existir na rede social digital, a verdade é que se encontra inativa há praticamente três anos. Os últimos posts apresentavam uma lógica transversal, além de incidirem também sobre a divulgação de eventos/manifestações/vigílias para causas nacionais, mas sobretudo internacionais, como é o caso de uma mobilização pró-democracia na Turquia. Em algumas publicações foram utilizados memes, e, de um modo geral, os posts não apresentam enquadramento, fazendo apenas apelo à mobilização. São cinco os elementos que surgem indicados como gestores da página.

Já a página do grupo "Democracia e Dívida" é atualizada diariamente. Em termos de conteúdos, a página apresenta sobretudo conteúdos próprios, que têm origem num blogue de um ativista, que se debruça sobre questões de economia política. São ainda publicadas notícias de meios de comunicação com o devido enquadramento temático. Mais recentemente verifica-se que alguns dos posts estão relacionados com a Covid-19 e sobretudo que há uma reiterada tentativa de associação da pandemia às forças imperialistas norte-americanas.

Também a página do grupo "FLAN Colectivo" apresenta uma periodicidade de publicação diária, por vezes são mesmo publicados vários conteúdos por dia. Para além de breves enquadramentos escritos, as publicações apresentam sobretudo imagens. É um movimento que continua a ter na comunicação visual a sua principal aposta, mantendo assim a tendência já verificada em 2013. As últimas publicações incidem sobretudo nas consequências económicas e sociais da Covid-19, em particular as consequências negativas da subida do desemprego e seu impacto na sociedade portuguesa. A página é gerida por dois elementos, um em Portugal e outro na Suíça.

Por fim, a página do grupo "Indignados Lisboa" é uma das que se mantém mais ativa, apresentando várias publicações por dia. É uma página que recorre sistematicamente a conteúdos de outras páginas também presentes na rede social digital, como a "Guilhotina.info" e a "Democracia e Dívida", partilhando estes conteúdos com um breve enquadramento. Os temas focados versam sobretudo na denúncia do poder financeiro e das elites económicas. Ultimamente tem apresentado publicações relacionadas com a precariedade e a vulnerabilidade de trabalhadores em face da Covid19.

De um modo geral, podemos considerar que, após o ciclo de protestos contra a austeridade, muitas destas páginas reduziram significativamente a sua atividade, o que pode ser explicado pelas mudanças verificadas no país, em termos políticos e sociais, mas também pelo facto de a sua ação surgir em momentos e em torno de 
acontecimentos específicos. Apesar de estes grupos ou movimentos se apresentarem como menos formais e, por conseguinte, com uma orgânica distinta das organizações mais tradicionais, como por exemplo os partidos ou os sindicatos, não podemos esquecer que, tirando proveito das tecnologias da comunicação e informação, estes grupos representam novos modelos de associativismo, cuja atividade se encontra quase sempre localizada no tempo e no espaço.

\section{Considerações finais}

Os movimentos sociais que se desenvolveram e proliferaram na esfera pública portuguesa nos últimos anos têm um claro lastro antiausteritário, fazendo uso em menor proporção da política antineoliberalista (Della Porta, 2017). No contexto da Grande Recessão - não deixa de ser notório o facto de estarmos perante a maior mobilização em Portugal, a 15 de setembro de 2012, que decorreu da reação a uma ofensiva liberalizadora do governo português de então, a coberto do memorando de entendimento com a Troika. Esta ação resultou num ciclo de protesto que se prolongou desde 2010 até ao verão de 2013 (Accornero e Pinto, 2015a; Accornero, 2019). Foi num momento de generalizado sentimento de desilusão, relativamente à promessa democrática das últimas quatro décadas, que os portugueses saíram em massa à rua contestando uma medida que Ihes "mexia diretamente no bolso". No fundo, foi a perceção de uma profunda injustiça, na qual se inscreveu a necessidade de praticar uma política de austeridade imposta de forma autoritária - em que quem estava a pagar era quem menos tinha contribuído para o pedido de resgate -, que levou as pessoas para a rua.

Estes movimentos emergem e têm uma forte ancoragem espácio-temporal, no sentido em que são muito o resultado de determinantes históricos, económicos e políticos de um Portugal sob intervenção externa. Esta característica é bem ilustrada pela própria origem etimológica da designação de alguns dos movimentos estudados, como são os casos do "Que se Lixe a Troika" ou do "O Povo é quem mais ordena", em que a reciclagem de uma "velha" máxima oriunda do tema escrito e interpretado por Zeca Afonso (diminutivo familiar de José Manuel Cerqueira Afonso dos Santos, conhecido cantor e compositor português), autor de "Grândola Vila Morena", canção escolhida pelo Movimento das Forças Armadas (MFA) para ser a segunda senha de sinalização da Revolução dos Cravos, com o refrão "O Povo é quem mais ordena", e que ficou celebre no Período Revolucionário em Curso (Prec). Este circunstancialismo estrutural está também patente em designações de outros movimentos como os "Indignados Lisboa", numa clara alusão ao movimento internacionalista dos "Indignados", celebrizado sobretudo em Espanha no mesmo período, o que confirma a sua forte circunscrição histórica, política e social.

Considerando um plano retrospetivo de análise, podemos classificar o "RiseUp Portugal" como um grupo ou movimento social nativo digital. Ao longo dos últimos anos 
JOÃO CARLOS SOUSA; RICARDO MORAIS

tem-se destacado por uma constância, mensurável quer na periodicidade das publicações, quer no tipo de conteúdos e causas que tem abraçado, o que o distingue de todos os outros. Lembre-se que este grupo surgiu originalmente na internet, em particular no Facebook, e por lá tem proliferado, perfil bem ilustrado ao ser o único dos oito movimentos analisados que ultrapassa largamente a marca dos cem mil seguidores e gostos. A esta tendência não será alheio o facto de ser um grupo que tem na causa ambientalista uma das suas bandeiras prioritárias. Denunciando ou chamando atenção para riscos, o "RiseUp Portugal", em entrevista e na voz dos seus ativistas entrevistados, denomina-se também de um meio de comunicação social alternativo. Todos os outros grupos detêm uma forte ancoragem espácio-temporal, como foi a causa da intervenção da Troika em Portugal. Ao caducar esta questão, também estes movimentos perderam alguns dos seus objetivos mais imediatos.

Este perspetivar retrospetivo remete-nos também para uma outra asserção, que é fundada nalguns indícios da genérica abordagem feita aos movimentos sociais estudados na sua atividade recente no Facebook. Em geral, os conteúdos partilhados e as discussões que, a jusante, têm sido feitas nas diversas páginas do Facebook têm como mote a pandemia de Covid-19. O "RiseUp Portugal", ao incidir a sua atenção tendencialmente nas causas relacionadas a esta, nomeadamente argumentando acerca do impacto da expansão da atividade agrícola e mineira nalgumas regiões do mundo e em particular na China, tem também destacado a interação entre seres humanos e espécies selvagens que são inaptamente portadores de fatores patogénicos adversos ao humano. Os restantes movimentos, ainda que num registo de alguma intermitência, têm feito as suas publicações mais no âmbito das consequências sociais e económicas que advêm da crise económica e da desaceleração económica mundial em resultado da pandemia de Covid-19. Esta asserção, não sendo definitiva nem totalmente assertiva, uma vez que não produzimos demonstração empírica que a validasse, constitui-se como uma potencial ponte para investigações próximas sobre movimentos sociais em rede no contexto mais amplo da pandemia de Covid-19.

Por outro lado, importa fazer um balanço ao modelo analítico implementado. Dirse-á que a dimensão "Dinâmica e a organização do debate" se revelou mais seletiva comparativamente à primeira ("Organização e informação"). O que pode ser lido como um indicador geral de que os movimentos sociais apostam mais no manuseamento e na partilha de conteúdos informativos do que no empreender das necessárias condições para um profícuo debate com contornos deliberativos.

Embora se perceba, através do discurso direto dos ativistas, que existe uma permanente necessidade de afastamento, e até, em alguns casos, de crítica aberta a organizações com níveis de institucionalização maiores, como os partidos políticos (cf. Meza e Tatagiba, 2016), ou mesmo os sindicatos (cf. Perez, 2019), a verdade é que a maioria dos entrevistados apresenta alguma herança de militância e pertença partidária a movimentos cívicos e políticos como o MAS (Movimento Alternativa Socialista). Foi ainda 
possível discernir relações de conhecimento mútuo entre vários ativistas de diferentes movimentos, o que, em última instância, nos leva a identificar uma espécie de "mercado da contestação", que tem na cidade de Lisboa o seu epicentro.

A componente reativa destes movimentos marca de forma transversal os grupos estudados. Com exceção do "Que se lixe a Troika", que tem este programa relativamente bem definido e resumido em três pontos, é a insípida ordem programática dos movimentos que se destaca. O tom geral é de crítica e pessimismo relativamente ao modo como o diálogo decorre entre os membros dos diferentes movimentos. Contudo, aqueles que têm uma natureza mais presencial revelam maior satisfação com os procedimentos comunicacionais e interacionais internos, como são os casos do "Indignados Lisboa" e do "Democracia e Dívida".

Em suma, os movimentos sociais aqui estudados caracterizam-se e diferenciamse entre si a partir dos seguintes indicadores: a fundação do movimento pode advir de uma mobilização coletiva em copresença ou através da iniciativa individual ou de restrito conjunto de atores; em geral não existe grande estruturação no nível da ordem programática; existe um efetivo investimento na circulação e na partilha de informação; a comunicação e a interação interna dão-se em circunstância com forte potencial conflituoso; não existe promoção da interação e da comunicação com atores externos ao movimento; existe alguma relutância e até mesmo constrangimentos em estabelecer interação com atores que solicitem informações sobre o movimento e as suas atividades.

O modelo construído e aplicado neste artigo revelou-se profícuo para a investigação, uma vez que nos permitiu discernir diferentes caraterísticas entre os oito movimentos sociais e com isso proceder à sua caracterização. Deste modo, é possível também aplicar este modelo a estruturas e atores políticos institucionais como são os partidos políticos e dessa forma estabelecer comparações que façam evoluir o campo de estudos. No fundo, argumentamos que este modelo serve a um desígnio fundamental em ciência, a replicação, e com isso ganham o conhecimento, a sociologia, as ciências da comunicação e o conhecimento em torno destes atores coletivos.

\section{Referências bibliográficas}

AcCoRnero, G. 'II wanted to carry out the revolution': activists' trajectories in Portugal from dictatorship to democracy". Social Movement Studies, vol. 18, no 3, p. 305-323, 2019.

Accornero, G.; Pinto, P. R. "'Brandos costumes?' Protesto e mobilização em Portugal sob a austeridade, 2010-2013". Estudos Ibero-Americanos, Porto Alegre, vol. 41, no 2, p. 393-421, $2015 a$.

\footnotetext{
. "'Mild mannered'? Protest and mobilisation in Portugal under austerity, 2010-2013". West European Politics, vol. 38, no 3, p. 491-515, 2015 b.

Amaral, I. "Citizens beyond Troika: media and anti-austerity protests in Portugal". International Journal of Communication, vol. 14, p. 3.309-3.329, 2020.
}

Barreto, A. Tempo de incerteza. Lisboa, Portugal: Relógio d'Água, 2004. 
JOÃO CARLOS SOUSA; RICARDO MORAIS

Baumgarten, B. "Geração à rasca and beyond: mobilizations in Portugal after 12 March 2011". Current Sociology, vol. 61, no 4, p. 457-473, 2013.

BAUMgarten, B.; DíEZ, R. "More than a copy paste: the spread of Spanish frames and events to Portugal". Journal of Civil Society, vol. 13, no 3, p. 247-266, 2017.

Berelson, B. Content analysis in communication research. Michigan: Free Press, 1952.

Berger, A. A. Media and communication research methods: an introduction to qualitative and quantitative approaches. $4^{a}$ ed. London: Sage, 2016.

BOYD, D. M.; ELLISON, N. B. "Social network sites: definition, history and scholarship". Journal of Computer-Mediated Communication, vol. 13, no 1, p. 210-230, 2007.

Bruns, A. Blogs, Wikipedia, Second Life, and beyond: from production to produsage. New York: Peter Lang, 2008.

CARdoso, G; SAntos, S.; Telo, D. (orgs.). Jornalismo em tempo de crise. Lisboa: Editora Mundos Sociais, 2017.

CARdoso, G., et al. Práticas e consumos digitais noticiosos dos portugueses em 2016. Relatórios OberCom, Lisboa, 2017. Disponível em: <https://obercom.pt/wpcontent/uploads/2017/04/2017_OBERCOM_SAPO_B.pdf>. Acesso em: 18 ago. 2019.

CARLOS, E. "Mudanças e continuidades no movimento de direitos humanos: padrões organizacionais, relacionais e discursivos". Opinião Pública, Campinas, vol. 20, n 3, p. 450-479, 2014.

CASTELls, M. A galáxia internet. Reflexões sobre a internet. Negócios e sociedade. Lisboa: Fundação Calouste Gulbenkian [2001], 2004.

. A sociedade em rede. A era da informação: economia, sociedade e cultura, vol. I. $3^{a}$ ed. Lisboa: Fundação Calouste Gulbenkian [1996], 2007.

- Redes de indignação e esperança: movimentos sociais na era da internet. Lisboa:

Fundação Calouste Gulbenkian, 2013.

CHOMSKY, N. Occupy. Lisboa: Antigona, 2013.

Coleman, S. Can the internet strengthen democracy? Democratic futures. Cambridge: Polity Press, 2017.

CorreiA, J. C. "O papel das redes digitais na configuração epistemológica dos debates de sociedade". Estudos em Comunicação, Covilhã, vol. 15, p. 77-92, 2014.

Social media and political participation. The Portuguese 'indignados' case. In: FIgUEIRAS, R.; ESPÍRITO SANTO, P. (eds.). Beyond the internet: unplugging the protest movement wave. New York: Routledge, p. 99-135, 2016.

CROUCHER, S. M.; CRONN-MillS, D. Understanding communication research methods: a theoretical and practical approach. New York: Routledge, 2015.

DAder, J. L.; Cheng, L. Análisis cuantitativo y cualitativo de las web de partidos. In: BLANCO, V. F. S. (coord.). Cibercampaña. Cauces y diques para la participación. Las elecciones generales de 2008 y su proyección tecnopolítica. Madrid: Editorial Complutense S.A., p. 129-143, 2011.

DAHLGREN, P. "The internet, public spheres, and political communication: dispersion and deliberation". Political Communication, vol. 22, no 2, p. 147-162, 2005. 
DAHLGREN, P. Social media and political participation. Discourse and deflection. In: FUCHS, C.; SANDOVAL, M. (eds.). Routledge studies in science, technology and society: critique, social media and the information society. London: Routlegde, p. 191-202, 2014.

DAVID, I. Portuguese democracy under austerity: politics in exceptional times. In: PARKER, O.; TSAROUHAS, D. (eds.). Crisis in the Eurozone periphery. The political economies of Greece, Spain, Ireland and Portugal. Cham, Switzerland: Palgrave Macmillan, p. 161-180, 2018.

DelLa PORTA, D. "Political economy and social movement studies: the class basis of anti-austerity protests". Anthropological Theory, vol. 17, no 4, p. 453-473, 2017.

DeLLA PORTA, D., et al. Legacies and memories in movements. Oxford: Oxford University Press, 2018.

DíEZ, R. "The 'Indignados' in space and time: transnational networks and historical roots". Global Society, vol. 31, no 1, p. 43-64, 2017.

Figueiras, R. A mediatização da política na era das redes sociais. Lisboa: Alêtheia Editores, 2017.

FigUeIRAS, R.; ESPÍRITO SANTO, P. (eds.). Beyond the internet: unplugging the protest movement wave. New York: Taylor and Francis Inc, 2016.

Figueiras, R.; Espírito Santo, P.; CUnha, I. F. (coords.). Democracy at work: pressure and propaganda in Portugal and Brazil. Coimbra: Imprensa da Universidade de Coimbra, 2015.

FISHMAN, R. M. "Democratic practice after the revolution: the case of Portugal and beyond". Politics \& Society, vol. 39, no 2, p. 233-26, 2011.

FISHMAN, R. M. Democratic practice: origins of the Iberian divide in political inclusion. Oxford: Oxford University Press, 2019.

Freire, A. Para lá da "Geringonça": o governo de esquerdas em Portugal e na Europa. Lisboa: Edições Contraponto, 2017.

FuCHS, C. "Behind the news. Social media, riots, and revolutions". Capital \& Class, vol. 36, no 3, p. 383-391, 2012.

Critique of the political economy of informational capitalism and social media. In: FUCHS, C.; SANDOVAL, M. (eds.). Routledge studies in science, technology and society: critique, social media and the information society. London: Routlegde, 2014a.

Zero Books, 2014b.

OccupyMedia! The Occupy Movement and social media in crisis capitalism. Winchester:

FuCHS, C.; SANDOVAL, M. Critique, social media and the information society in the age of capitalist crisis. In: FuCHS, C.; SANDOVAL, M. (eds.). Routledge studies in science, technology and society: critique, social media and the information society. London: Routlegde, p. 1-47, 2014.

GalRão, M.; TAVARES, R. Como Costa montou a geringonça em 54 dias: os bastidores do acordo histórico da esquerda. Alfragide: Lua de Papel, 2016.

Ghiglione, R.; MAtAlon, B. O inquérito. 4aa ed. Oeiras: Celta Editora [1977], 2001.

KRIPPENDORF, K. Content analysis: an introduction to its methodology. London: Sage, 1980. 
MezA, H.; TATAgiba, L. "Movimentos sociais e partidos políticos: as relações entre o movimento feminista e o sistema de partidos na Nicarágua (1974-2012)". Opinião Pública, Campinas, vol. 22, no 2, p. 350-384, 2016.

MORAIS, R.; SOUSA, J. "Do envolvimento associativo à mobilização cívica: o potencial das redes sociais". In: VII Congresso de Sociologia - Sociedade, Crise e Reconfigurações, organizado pela Associação Portuguesa de Sociologia, Faculdade de Letras da Universidade do Porto, Portugal, 2012.

NUNES, C. "Portugal and Spain in the international protest cycles: from global justice movement to anti-austerity protests". In: Costa Pinto, A.; TeiXeIRA C. P. (eds.). Political institutions and democracy in Portugal. Assessing the impact of the eurocrisis. Cham, Switzerland: Palgrave Macmillan, p. 195-213, 2019.

OLSSON, T. "The architecture of participation": For citizens or consumers? In: FUCHS, C.; SANDOVAL, M. (eds.). Routledge studies in science, technology and society: critique, social media and the information society. London: Routlegde, p. 203-215, 2014.

Pereira, M. A. "Movimentos sociais e democracia: a tensão necessária". Opinião Pública, vol. 18, no 1 , p. $68-87,2012$.

PEREZ, O. C. "Relações entre coletivos com as Jornadas de Junho". Opinião Pública, Campinas, vol. 25, n० 3, p. 577-596, 2019.

PORTOS, M.; CARVALHO, T. "Alliance building and eventful protests: comparing Spanish and Portuguese trajectories under the great recession". Social Movement Studies, vol 1, no 1, p. 1-20, 2019.

RECUERO, R. Introdução à análise de redes sociais online. Salvador: Edufba, 2017.

SilVA, C. T. "Civic participation and demonstrations in Portugal (2011-2012)". European Journal of Multidisciplinary Studies, vol. 4, no 3, p. 49-55, 2019.

SouSA, J. C. "Participação política no Facebook. Continuidades e reconfigurações". Dissertação de Mestrado defendida no Departamento de Sociologia da Universidade da Beira Interior, Covilhã, 2013. Disponível em: <https://catalogo.ubi.pt/cgi-bin/koha/opac-detail.pl?biblionumber=96446> . Acesso em: mar. 2021.

TAtagiba, L.; PATERniani, S. Z.; TRindade, T. A. "Ocupar, reivindicar, participar: sobre o repertório de ação do movimento de moradia de São Paulo". Opinião Pública, Campinas, vol. 18, no 2, p. 399426, 2012.

TEJERINA, B., et al. "From indignation to occupation: a new wave of global mobilization". Current Sociology, vol. 61, no 4, p. 377, 2013.

TeIXEIRA, C. P. Qualidade da democracia em Portugal. Lisboa: Fundação Francisco Manuel dos Santos, 2018.

VALA, J. Análise de conteúdo. In: Silva, A. S.; PInTo, J. M. (orgs.). Metodologia das ciências sociais. $12^{\mathrm{a}}$ ed. Porto: Edições Afrontamento, p. 101-128, 2003. 


\section{Anexo I}

Classificação e avaliação dos movimentos/organizações

Tabela I

RiseUp Portugal - Organização e informação

\begin{tabular}{|c|c|c|c|c|}
\hline $1^{a}$ Organização e informação & Pontuação & Ponderação & Totais & Itens \\
\hline $\begin{array}{l}\text { 1.1. Apresentação da organização/do movimento e sua } \\
\text { organização }\end{array}$ & 2 & 1 & 2 & 2 \\
\hline 1.2. Atualidade noticiosa/mediática e política & 6 & 2 & 12 & $1-2-3$ \\
\hline 1.3. Informação de outras organizações e instituições & 6 & 3 & 18 & $1-2-3$ \\
\hline $\begin{array}{l}\text { 1.4. Informação de ações do movimento/da } \\
\text { organização }\end{array}$ & 6 & 4 & 24 & $1-2-3$ \\
\hline $\begin{array}{l}\text { 1.5. Informações que revelem objetivos e orientações } \\
\text { programáticas }\end{array}$ & 4 & 5 & 20 & $2-3$ \\
\hline Totais & 24 & - & 76 & - \\
\hline
\end{tabular}

Fonte: Elaboração própria.

Tabela II

RiseUp Portugal - Dinâmica organizativa do debate

\begin{tabular}{|c|c|c|c|c|}
\hline $2^{a}$ Dinâmica organizativa do debate & Pontuação & Ponderação & Totais & Itens \\
\hline $\begin{array}{l}\text { 2.1. Possibilidade de correspondência via postal e/ou outras } \\
\text { plataformas }\end{array}$ & 4 & 1 & 4 & $1-3$ \\
\hline 2.2. Bloco de notas & 2 & 2 & 4 & 1 \\
\hline $\begin{array}{l}\text { 2.3. Complexidade do enquadramento dos posts da } \\
\text { administração }\end{array}$ & 6 & 3 & 18 & $1-2-3$ \\
\hline $\begin{array}{l}\text { 2.4. Comentários da própria página aos seus posts e dos } \\
\text { seguidores }\end{array}$ & 2 & 4 & 8 & 1 \\
\hline 2.5. Correspondência por mensagem privada & 6 & 5 & 30 & $1-2-3$ \\
\hline Totais & 20 & - & 64 & - \\
\hline
\end{tabular}

Fonte: Elaboração própria.

Realização: Dia 16 de junho de 2013, 12h40 - 13h20

Nota: Permite posts aos seguidores. Bloco de Notas duplamente desatualizado. Do lado da organização/do movimento, o último post data de 4 de setembro de 2012. No que concerne aos seguidores, a última atualização é de 12 de abril de 2013.

Tabela III

Indignados Lisboa - Organização e informação

\begin{tabular}{|c|c|c|c|c|}
\hline $1^{\text {a }}$ Organização e informação & Pontuação & Ponderação & Totais & Itens \\
\hline $\begin{array}{l}\text { 1.1. Apresentação da organização/do movimento e sua } \\
\text { organização }\end{array}$ & 4 & 1 & 4 & $2-3$ \\
\hline 1.2. Atualidade noticiosa/mediática e política & 6 & 2 & 12 & $1-2-3$ \\
\hline 1.3. Informação de outras organizações e instituições & 2 & 3 & 6 & 3 \\
\hline $\begin{array}{l}\text { 1.4. Informação de ações do movimento/da } \\
\text { organização }\end{array}$ & 4 & 4 & 16 & $1-2$ \\
\hline $\begin{array}{l}\text { 1.5. Informações que revelem objetivos e orientações } \\
\text { programáticas }\end{array}$ & 4 & 5 & 20 & $1-2$ \\
\hline Totais & 20 & - & 58 & - \\
\hline
\end{tabular}

Fonte: Elaboração própria 
Tabela IV

Indignados Lisboa - Dinâmica organizativa do debate

\begin{tabular}{|l|c|c|c|c|}
\hline 2a Dinâmica organizativa do debate & Pontuação & Ponderação & Totais & Itens \\
\hline $\begin{array}{l}\text { 2.1. Possibilidade de correspondência via postal e/ou outras } \\
\text { plataformas }\end{array}$ & 4 & 1 & 4 & $1-3$ \\
\hline 2.2 . Bloco de Notas & 0 & 2 & 0 & 0 \\
\hline $\begin{array}{l}\text { 2.3. Complexidade do enquadramento dos posts da } \\
\text { administração }\end{array}$ & 6 & 3 & 18 & $1-2-3$ \\
\hline $\begin{array}{l}\text { 2.4. Comentários da própria página aos seus posts e dos } \\
\text { seguidores }\end{array}$ & 2 & 4 & 8 & 1 \\
\hline 2.5. Correspondência por mensagem privada & 6 & 5 & 30 & $1-2-3$ \\
\hline Totais & 18 & - & 60 & - \\
\hline
\end{tabular}

Fonte: Elaboração própria.

Realização: Dia 16 de junho de 2013, $13 \mathrm{~h} 25$ - $14 \mathrm{~h} 10$.

Tabela V

O Povo é Quem Mais Ordena - Organização e informação

\begin{tabular}{|l|c|c|c|c|}
\hline 1a Organização e informação & Pontuação & Ponderação & Totais & Itens \\
\hline $\begin{array}{l}\text { 1.1. Apresentação da organização/do movimento e sua } \\
\text { organização }\end{array}$ & 6 & 1 & 6 & $1-2-3$ \\
\hline 1.2. Atualidade noticiosa/mediática e política & 2 & 2 & 4 & 2 \\
\hline 1.3. Informação de outras organizações e instituições & 2 & 3 & 6 & 3 \\
\hline $\begin{array}{l}\text { 1.4. Informação de ações do movimento/da } \\
\text { organização }\end{array}$ & 2 & 4 & 8 & 1 \\
\hline $\begin{array}{l}\text { 1.5. Informações que revelem objetivos e orientações } \\
\text { programáticas }\end{array}$ & 6 & 5 & 30 & $1-2-3$ \\
\hline Totais & 18 & - & 54 & - \\
\hline
\end{tabular}

Fonte: Elaboração própria.

Tabela VI

O Povo é Quem Mais Ordena - Dinâmica organizativa do debate

\begin{tabular}{|l|c|c|c|c|}
\hline 2a Dinâmica organizativa do debate & Pontuação & Ponderação & Totais & Itens \\
\hline $\begin{array}{l}\text { 2.1. Possibilidade de correspondência via postal e/ou outras } \\
\text { plataformas }\end{array}$ & 2 & 1 & 2 & 1 \\
\hline 2.2. Bloco de notas & 4 & 2 & 0 & 0 \\
\hline $\begin{array}{l}\text { 2.3. Complexidade do enquadramento dos posts da } \\
\text { administração }\end{array}$ & 6 & 3 & 18 & $1-2-3$ \\
\hline $\begin{array}{l}\text { 2.4. Comentários da própria página aos seus posts e dos } \\
\text { seguidores }\end{array}$ & 2 & 4 & 8 & 1 \\
\hline 2.5. Correspondência por mensagem privada & 0 & 5 & 0 & 0 \\
\hline Totais & 10 & - & 28 & - \\
\hline
\end{tabular}

Fonte: Elaboração própria.

Realização: Dia 16 de junho de 2013, $20 \mathrm{~h} 45$ - 21h15.

Notas: Permite posts dos seguidores. Não tem Bloco de Notas. 
Tabela VII

Democracia e Dívida - Organização e informação

\begin{tabular}{|l|c|c|c|c|}
\hline 1a Organização e informação & Pontuação & Ponderação & Totais & Itens \\
\hline $\begin{array}{l}\text { 1.1. Apresentação da organização/do movimento e } \\
\text { sua organização }\end{array}$ & 4 & 1 & 4 & $2-3$ \\
\hline 1.2. Atualidade noticiosa/mediática e política & 6 & 2 & 12 & $1-2-3$ \\
\hline $\begin{array}{l}\text { 1.3. Informação de outras organizações e } \\
\text { instituições }\end{array}$ & 0 & 3 & 0 & 0 \\
\hline $\begin{array}{l}\text { 1.4. Informação de ações do movimento/da } \\
\text { organização }\end{array}$ & 6 & 4 & 24 & $1-2-3$ \\
\hline $\begin{array}{l}\text { 1.5. Informações que revelem objetivos e } \\
\text { orientações programáticas }\end{array}$ & 4 & 5 & 20 & $2-3$ \\
\hline Totais & 20 & - & 66 & - \\
\hline
\end{tabular}

Fonte: Elaboração própria.

Tabela VIII

Democracia e Dívida - Dinâmica organizativa do debate

\begin{tabular}{|l|c|c|c|c|}
\hline 2a Dinâmica organizativa do debate & Pontuação & Ponderação & Totais & Itens \\
\hline $\begin{array}{l}\text { 2.1. Possibilidade de correspondência via postal e/ou outras } \\
\text { plataformas }\end{array}$ & 4 & 1 & 4 & $1-3$ \\
\hline 2.2. Bloco de notas & 6 & 2 & 12 & $1-2-3$ \\
\hline $\begin{array}{l}\text { 2.3. Complexidade do enquadramento dos posts da } \\
\text { administração }\end{array}$ & 4 & 3 & 12 & $1-2$ \\
\hline $\begin{array}{l}\text { 2.4. Comentários da própria página aos seus posts e dos } \\
\text { seguidores }\end{array}$ & 4 & 4 & 16 & $1-3$ \\
\hline 2.5. Correspondência por mensagem privada & 6 & 5 & 30 & $1-2-3$ \\
\hline Totais & 24 & - & 74 & - \\
\hline
\end{tabular}

Fonte: Elaboração própria.

Realização: Dia 16 de junho de 2013, $19 \mathrm{~h} 05$ - $19 \mathrm{~h} 35$.

Notas: Permite posts aos seguidores. Não há Bloco de notas.

Tabela IX

Artigo $21^{\circ}$ - Organização e informação

\begin{tabular}{|c|c|c|c|c|}
\hline 1 a Organização e informação & Pontuação & Ponderação & Totais & Itens \\
\hline $\begin{array}{l}\text { 1.1. Apresentação da organização/do movimento e sua } \\
\text { organização }\end{array}$ & 2 & 1 & 2 & 3 \\
\hline 1.2. Atualidade noticiosa/mediática e política & 6 & 2 & 12 & $1-2-3$ \\
\hline 1.3. Informação de outras organizações e instituições & 6 & 3 & 18 & $1-2-3$ \\
\hline 1.4. Informação de ações do movimento/da organização & 4 & 4 & 16 & $1-2$ \\
\hline $\begin{array}{l}\text { 1.5. Informações que revelem objetivos e orientações } \\
\text { programáticas }\end{array}$ & 2 & 5 & 10 & 2 \\
\hline Totais & 20 & - & 58 & - \\
\hline
\end{tabular}

Fonte: Elaboração própria. 
Tabela X

Artigo $21^{\circ}$ - Dinâmica organizativa do debate

\begin{tabular}{|c|c|c|c|c|}
\hline $2^{a}$ Dinâmica organizativa do debate & Pontuação & Ponderação & Totais & Itens \\
\hline $\begin{array}{l}\text { 2.1. Possibilidade de correspondência via postal e/ou } \\
\text { outras plataformas }\end{array}$ & 2 & 1 & 2 & 1 \\
\hline 2.2. Bloco de notas & 2 & 2 & 4 & 1 \\
\hline $\begin{array}{l}\text { 2.3. Complexidade do enquadramento dos posts da } \\
\text { administração }\end{array}$ & 6 & 3 & 9 & $1-2-3$ \\
\hline $\begin{array}{l}\text { 2.4. Comentários da própria página aos seus posts e } \\
\text { dos seguidores }\end{array}$ & 2 & 4 & 8 & 1 \\
\hline 2.5. Correspondência por mensagem privada & 0 & 5 & 0 & 0 \\
\hline Totais & 12 & - & 23 & - \\
\hline
\end{tabular}

Fonte: Elaboração própria.

Realização: Dia 16 de junho de 2013, 18h-18h55.

Notas: Permite posts aos seguidores.

Notas: Permite posts aos seguidores. Bloco de Notas duplamente desatualizado. No que toca ao movimento/organização a última atualização data de 8 de junho de 2011 . No que diz respeito à parte dedicada aos seguidores, a última atualização data de 14 de abril de 2013.

Tabela XI

15 Outubro - Organização e informação

\begin{tabular}{|c|c|c|c|c|}
\hline 1 a Organização e informação & Pontuação & Ponderação & Totais & Itens \\
\hline $\begin{array}{l}\text { 1.1. Apresentação da organização/do movimento e sua } \\
\text { organização }\end{array}$ & 4 & 1 & 4 & $2-3$ \\
\hline 1.2. Atualidade noticiosa/mediática e política & 4 & 2 & 8 & $2-3$ \\
\hline 1.3. Informação de outras organizações e instituições & 4 & 3 & 12 & $2-3$ \\
\hline $\begin{array}{l}\text { 1.4. Informação de ações do movimento/da } \\
\text { organização }\end{array}$ & 6 & 4 & 24 & $1-2-3$ \\
\hline $\begin{array}{l}\text { 1.5. Informações que revelem objetivos e orientações } \\
\text { programáticas }\end{array}$ & 4 & 5 & 20 & $1-2$ \\
\hline Totais & 22 & - & 68 & - \\
\hline
\end{tabular}

Fonte: Elaboração própria.

Tabela XII

15 Outubro - Dinâmica organizativa do debate

\begin{tabular}{|c|c|c|c|c|}
\hline $2^{a}$ Dinâmica organizativa do debate & Pontuação & Ponderação & Totais & Itens \\
\hline $\begin{array}{l}\text { 2.1. Possibilidade de correspondência via postal e/ou outras } \\
\text { plataformas }\end{array}$ & 2 & 1 & 2 & 1 \\
\hline 2.2. Bloco de notas & 4 & 2 & 8 & $1-2$ \\
\hline $\begin{array}{l}\text { 2.3. Complexidade do enquadramento dos posts da } \\
\text { administração }\end{array}$ & 6 & 3 & 18 & $1-2-3$ \\
\hline $\begin{array}{l}\text { 2.4. Comentários da própria página aos seus posts e dos } \\
\text { seguidores }\end{array}$ & 2 & 4 & 8 & 1 \\
\hline 2.5. Correspondência por mensagem privada & 6 & 5 & 30 & $1-2-3$ \\
\hline Totais & 20 & - & 66 & - \\
\hline
\end{tabular}

Fonte: Elaboração própria.

Realização: Dia 16 de junho de 2013, 19h40-20h.

Notas: Não permite posts aos seguidores. Tem Bloco de notas atualizado (4 de junho de 2013). No que toca aos seguidores, a última atualização é de 15 de novembro de 2012. 
Tabela XIII

Que se Lixe a Troika - Organização e informação

\begin{tabular}{|l|c|c|c|c|}
\hline 1a Organização e informação & Pontuação & Ponderação & Totais & Itens \\
\hline $\begin{array}{l}\text { 1.1. Apresentação da organização/do movimento e sua } \\
\text { organização }\end{array}$ & 4 & 1 & 4 & $2-3$ \\
\hline 1.2. Atualidade noticiosa/mediática e política & 6 & 2 & 12 & $1-2-3$ \\
\hline 1.3. Informação de outras organizações e instituições & 4 & 3 & 12 & $2-3$ \\
\hline $\begin{array}{l}\text { 1.4. Informação de ações do movimento/da } \\
\text { organização }\end{array}$ & 6 & 4 & 24 & $1-2-3$ \\
\hline $\begin{array}{l}\text { 1.5. Informações que revelem objetivos e orientações } \\
\text { programáticas }\end{array}$ & 6 & 5 & 30 & $1-2-3$ \\
\hline Totais & 26 & - & 82 & - \\
\hline
\end{tabular}

Fonte: Elaboração própria.

Tabela XIV

Que se Lixe a Troika - Dinâmica organizativa do debate

\begin{tabular}{|c|c|c|c|c|}
\hline $2^{a}$ Dinâmica organizativa do debate & Pontuação & Ponderação & Totais & Itens \\
\hline $\begin{array}{l}\text { 2.1. Possibilidade de correspondência via postal e/ou outras } \\
\text { plataformas }\end{array}$ & 4 & 1 & 4 & $1-3$ \\
\hline 2.2. Bloco de notas & 4 & 2 & 8 & $1-3$ \\
\hline $\begin{array}{l}\text { 2.3. Complexidade do enquadramento dos posts da } \\
\text { administração }\end{array}$ & 2 & 3 & 6 & 1 \\
\hline $\begin{array}{l}\text { 2.4. Comentários da própria página aos seus posts e dos } \\
\text { seguidores }\end{array}$ & 2 & 4 & 8 & 1 \\
\hline 2.5. Correspondência por mensagem privada & 0 & 5 & 0 & 0 \\
\hline Totais & 12 & - & 26 & - \\
\hline
\end{tabular}

Fonte: Elaboração própria.

Realização: Dia 15 de junho de 2013, 21 h55 - 23h.

Notas: Não permite posts. No Bloco de Notas permite, mas a última atualização é de 14 de abril de 2013.

Tabela XV

FLAN Colectivo - Organização e informação

\begin{tabular}{|c|c|c|c|c|}
\hline $1^{a}$ Organização e informação & Pontuação & Ponderação & Totais & Itens \\
\hline $\begin{array}{l}\text { 1.1. Apresentação da organização/do movimento e } \\
\text { sua organização }\end{array}$ & 4 & 1 & 4 & $2-3$ \\
\hline 1.2. Atualidade noticiosa/mediática e política & 2 & 2 & 4 & 2 \\
\hline $\begin{array}{l}\text { 1.3. Informação de outras organizações e } \\
\text { instituições }\end{array}$ & 2 & 3 & 6 & 3 \\
\hline $\begin{array}{l}\text { 1.4. Informação de ações do movimento/da } \\
\text { organização }\end{array}$ & 4 & 4 & 16 & $1-2$ \\
\hline $\begin{array}{l}\text { 1.5. Informações que revelem objetivos e } \\
\text { orientações programáticas }\end{array}$ & 2 & 5 & 10 & 1 \\
\hline Totais & 12 & - & 40 & - \\
\hline
\end{tabular}

Fonte: Elaboração própria. 
Tabela XVI

FLAN Colectivo - Dinâmica organizativa do debate

\begin{tabular}{|c|c|c|c|c|}
\hline $2^{a}$ Dinâmica organizativa do debate & Pontuação & Ponderação & Totais & Itens \\
\hline $\begin{array}{l}\text { 2.1. Possibilidade de correspondência via postal e/ou outras } \\
\text { plataformas }\end{array}$ & 4 & 1 & 4 & $1-3$ \\
\hline 2.2. Bloco de notas & 0 & 2 & 0 & 0 \\
\hline $\begin{array}{l}\text { 2.3. Complexidade do enquadramento dos posts da } \\
\text { administração }\end{array}$ & 4 & 3 & 12 & $1-3$ \\
\hline $\begin{array}{l}\text { 2.4. Comentários da própria página aos seus posts e dos } \\
\text { seguidores }\end{array}$ & 0 & 4 & 0 & 0 \\
\hline 2.5. Correspondência por mensagem privada & 0 & 5 & 0 & 0 \\
\hline Totais & 8 & - & 16 & - \\
\hline
\end{tabular}

Fonte: Elaboração própria.

Realização: Dia 16 de junho de 2013, 20 h25 - 20 h40.

Notas: Não permite posts dos seguidores. Não tem Bloco de Notas.

Tabela XVII

Registo do indicador 2.5 - Correspondência por mensagem privada

\begin{tabular}{|l|c|c|}
\hline Organização/movimento & $\begin{array}{c}\text { Hora de } \\
\text { visualização }\end{array}$ & Hora/data de resposta \\
\hline Que se Lixe a Troika & - & - \\
\hline Indignados Lisboa & - & $12 \mathrm{~h} 43,5$ de junho \\
\hline Democracia e Dívida & $9 \mathrm{~h} 51,5$ de junho & $20 \mathrm{~h} 57,9$ de junho \\
\hline O Povo é Quem Mais Ordena & - & - \\
\hline RiseUp Portugal & $13 \mathrm{~h} 20,5$ de junho & $17 \mathrm{~h} 31,5$ de junho \\
\hline Artigo 210 & $11 \mathrm{~h} 55,5$ de junho & - \\
\hline 15 Outubro & $9 \mathrm{~h} 51,5$ de junho & $09 \mathrm{~h} 51,5$ de junho \\
\hline FLAN Colectivo & $13 \mathrm{~h} 55,5$ de junho & - \\
\hline
\end{tabular}

Fonte: Elaboração própria.

\section{Anexo II - Guião das entrevistas \\ Organização e informação}

$1^{\text {a }}$ Como é que surgiu a Organização (...)? Identifique-me uma ou várias das principais finalidades da Organização (...)? Pode hierarquizá-las? Quando acha que deixou de fazer sentido a existência da Organização?

$2^{a}$ Quantos elementos compõem a Organização? O grupo de fundadores já se conhecia anteriormente? Como a Organização se diferencia do modo de organização dos partidos políticos? Pensa vir a tornar-se um partido? Acha que as suas atividades são suficientes para mudar a situação política?

$3^{a}$ Com que frequência o grupo se reúne? O que leva à marcação dessas reuniões? O grupo atua e trabalha de modo regular ou em função de factos que vão emergindo e que são contrários aos seus objetivos? Há delegação de responsabilidades e de tarefas? 
$4^{a}$ De que modo é tomada a decisão de realizar um evento? Participam todos nas decisões? Quem tem mais iniciativa? Há iniciativas propostas pelos seguidores? Trabalham todos na organização dos eventos ou há sempre um (o mesmo?) núcleo duro?

\section{Dinâmica organizativa do debate}

$5^{a}$ A presença da Organização (...) no Facebook surge em que contexto? Já existia noutras plataformas (blog-site) antes da sua presença no Facebook? Tem algum mecanismo de comunicação interna que faça uso da rede digital? Que diferenças apresenta o Facebook em face de outros artefactos e/ou meios de mobilização?

6a Como a Organização se relaciona com os meios de comunicação social de massas? Como perceciona o papel dos meios de comunicação de massa, seja na cobertura da atividade da sua Organização, seja na cobertura dos demais? Que meio de comunicação torna mais visível a sua atividade? Porquê?

7 a Considera que os objetivos da sua Organização se sobrepõem aos objetivos de outras organizações existentes? Considera que existe um trabalho coletivo? Se sim, acha que esse trabalho é desenvolvido de forma articulada?

$8^{a}$ Como perceciona o trabalho desenvolvido pela sua Organização, considerando o trabalho das Organizações da mesma natureza?

9a Considerando todas as Organizações que fazem uso do Facebook para as suas ações, que critérios usaria para os distinguir uns aos outros? No fundo, categorizando-os. Por que motivos não luta dentro de organizações e partidos já existentes?

10a Há algum tipo de contacto formal e/ou informal com outras organizações nacionais e/ou internacionais? Como e em que termos se processa esse relacionamento? E com as organizações mais institucionalizadas, como os sindicatos e partidos políticos?

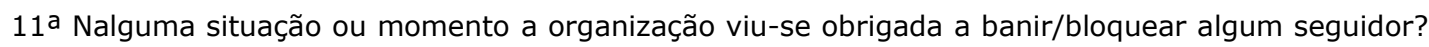
Porquê?

$12^{a}$ Perfil do inquirido: Idade; Habilitações académicas; Ocupação profissional

\section{Abstract}

Civic and political mobilization in the era of social networks: an analysis of the action of social movements on Facebook

In this article, we analyze the role of Facebook as a tool that articulates the daily practices of social movements, both in their internal organization and in communication and interaction with external 
elements. The methodological proposal involves the implementation of a mixed-methods approach, through content analysis of the Facebook pages of the eight movements studied and six face-to-face interviews with activists. The main results reveal that there is a strong anchoring of the movements to the broader political picture of the social and political crisis and intervention of the Troika, assuming their antagonism as their main objective. We also observed that, although they were successful in mobilizing a large part of the Portuguese population, the truth is that the mobilizing blaze was limited in time. The constructed model proved to be robust and flexible, which makes it possible to replicate it in future research in the field of political sociology.

Keywords: civic mobilization; political participation; social networks; Facebook

\section{Resumen}

Movilización cívica y política en la era de las redes sociales: un análisis de la acción de los movimientos sociales en Facebook

En este artículo se analiza el papel de Facebook como herramienta articuladora de las prácticas cotidianas dentro de los movimientos sociales, tanto en su organización interna como en la comunicación e interacción con elementos externos. La propuesta metodológica implica la implementación de una metodología mixta, mediante un análisis de contenido de las cuentas de Facebook de los ocho movimientos estudiados, así como la realización de seis entrevistas cara a cara con activistas. Los principales resultados revelan que existe un fuerte anclaje, por parte de los movimientos, tanto en el panorama político más amplio de la crisis social y política, como en la intervención de la Troika, asumiendo como principal objetivo su desafío. También observamos que, si bien lograron movilizar a gran parte de la población portuguesa, lo cierto es que el efecto de movilización fue limitado en el tiempo. El modelo construido demostró ser robusto y flexible, lo que permite replicarlo en futuras investigaciones en el campo de la sociología política.

Palabras clave: movilización cívica; participación política; redes sociales; Facebook

\section{Résumé}

Mobilisation civique et politique à l'ère des réseaux sociaux: une analyse de l'action des mouvements sociaux sur Facebook

Dans cet article, nous analysons le rôle de Facebook comme outil d'articulation des pratiques quotidiennes au sein des mouvements sociaux, tant dans son organisation interne que dans la communication et l'interaction avec des éléments externes. La démarche méthodologique implique la mise en œuvre d'une méthodologie mixte, à travers une analyse de contenu aux pages Facebook des huit mouvements étudiés et la réalisation de six entretiens en face à face avec des militants. Les principaux résultats révèlent qu'il existe un ancrage fort des mouvements dans le tableau politique plus large de la crise sociale et politique et de l'intervention de la Troïka, assumant comme objectif principal son défi. Nous avons également observé que, bien que réussissant à mobiliser une grande partie de la population portugaise, la vérité est que la lueur mobilisatrice était limitée dans le temps. Le modèle construit s'est avéré robuste et flexible, ce qui permet de le reproduire dans de futures recherches dans le domaine de la sociologie politique.

Mots-clés: mobilisation civique; participation politique; réseaux sociaux; Facebook

Artigo submetido à publicação em 20 de fevereiro de 2020 . Versão final aprovada em 15 de janeiro de 2021.

Opinião Pública adota a licença Creative Commons CC-BY. 